\title{
Teil III: Das Projekt UnVergessen
}

\author{
Katrin Bente Karl
}

In diesem Teil des Buches steht eine genaue Schilderung des Projektes UnVergessen im Fokus. Die Darstellung beginnt bei der Entstehung der Projektidee, führt weiter zur Entwicklung des Projektes und einer detaillierten Beschreibung des Projektablaufes inkl. seiner curricularen Anbindung. Dem schließt sich die Weiterentwicklung und Ausrichtung auf das Forschende Lernen an. Somit wird hier der hochschuldidaktische Blick eingenommen. Ein eigener Abschnitt widmet sich den besonderen Herausforderungen, vor denen UnVergessen im Frühjahr 2020 durch die Corona-Pandemie stand und schildert die daraus hervorgegangenen neuen Aktivitäten und gestärkten Kontakte. Nachfolgend werden die diversen wissenschaftlichen Potenziale der durch die mehrjährige Projektarbeit gesammelten Erfahrungen und Daten verdeutlicht. Eindrücke über die Auswirkungen des Projektes auf die teilnehmenden Studierenden, ihre Persönlichkeitsbildung, Gruppenzusammenhalt und soziales Engagement runden diesen Teil ab.

K. B. Karl ( $\square)$

Seminar für Slavistik/Lotman-Institut, Ruhr-Universität Bochum, Bochum, Deutschland E-Mail: katrin.karl@ rub.de 


\section{Von der Idee zur ersten Projektrunde ${ }^{1}$}

Der Wissenschaft hängt allzu oft der Nimbus an, im Elfenbeinturm Erkenntnisse zu generieren, die kaum einen Weg nach außen in die ,echte“ Welt finden. Dies gilt gleichermaßen für die Linguistik - der Wissenschaft von der Sprache. Häufig hört man als Germanist die Frage, warum ein Deutschsprachiger denn noch Deutsch studieren müsse. Auf noch mehr Unverständnis trifft ein deutschsprachiger Mensch, der eine andere Sprache als seine Muttersprache, wie z. B. Russisch studiert: „Es gibt doch mehrere Millionen Menschen, die Russisch schon können, warum studierst du denn dann das?“”

Dabei gibt es sehr viele Bereiche, in denen studierte Linguist/innen - egal welcher Sprache - mit ihrem sprachlichen Wissen und analytischen Verfahren etwas in der Welt verändern können und reale Bedürfnisse aus der praktischen Erfahrung in die Wissenschaft tragen oder andersherum. Gerade im Bereich der Sprache ergeben sich viele Überschneidungen und gegenseitige Befruchtungen zwischen Anwendung und Wissenschaft, dies im Besonderen in Bereichen, in denen zwei oder mehr Sprachen aufeinandertreffen, wie es in unserer mehrsprachigen Gesellschaft mittlerweile alltäglich ist.

Ein solches Beispiel ist die Genese des Projektes UnVergessen, das seit dem Wintersemester 2016 an der Ruhr-Universität Bochum am Seminar für Slavistik/Lotman-Institut verankert ist. Den Ursprung nahm das Projekt, indem die Studentin Anna Tusche in ihrer Abschlussarbeit des Bachelor-Studiums die sprachliche Situation einer Frau beschrieb, die als russischsprachige Demenzerkrankte in einem deutschsprachigen Pflegeheim lebte und dort keine Möglichkeit

\footnotetext{
${ }^{1}$ Dieser Abschnitt, sowie die folgenden zwei weiteren Abschnitte bestehen aus z. T. wörtlich übernommenen, z. T. adaptierten Ausführungen von mir, die ich an anderer Stelle bereits publiziert habe. Da sich die jeweils geschilderten Inhalte decken, habe ich die Formulierungen hier übernommen und in einen aktualisierten Kontext gestellt. Bei allen übernommenen Textstücken handelt es sich ausschließlich um von mir formulierte Textteile.

In diesem Abschnitt habe ich vorrangig einen Artikel, der als Gastbeitrag in den BBE Europa-

Nachrichten mit dem Schwerpunkt „Bürgerschaftliches Engagement gegen Einsamkeit“ erschienen und unter der URL https://www.b-b-e.de/europa-nachrichten/europa-nachrichtennr-6-vom-972020/karl-universitaeres-engagement-gegen-einsamkeit/vergessen/ abrufbar ist, eingefügt (Karl, 2020). Die Weiterverwendung erfolgte in Absprache und mit freundlicher Genehmigung der BBE Europa-Nachrichten.

In den beiden Folgeabschnitten werden die Teile aus einem gemeinsamen Beitrag von Y. Behrens und mir (aus Karl \& Behrens, 2020) übernommen, die aus meiner Autorenschaft stammen. Hier erfolgte die Wiederverwendung und Anpassung an den neuen Inhalt mit Erlaubnis der Springer Nature Customer Service Centre GmbH für die angegebene Quelle (Karl \& Behrens, 2020).
} 
mehr hatte, ihre gewohnte Muttersprache zu sprechen. Sie wurde ausschließlich auf Deutsch gepflegt, hatte jedoch zugleich durch ihre Erkrankung ihre Deutschkenntnisse weitestgehend verloren. In dieser Arbeit wurden die daraus erwachsenden kommunikativen Herausforderungen für alle Beteiligten eindrucksvoll geschildert (vgl. Tusche, 2015). Die Lektüre dieser Arbeit, die Einblicke in die tägliche sprachliche Praxis bot, setzte einen Gedankenprozess bei mir als Betreuerin in Gang, der zunächst in der Recherche nach vergleichbaren Ergebnissen bzw. nach Zahlen vergleichbarer Schicksale mündete. Beides stellte sich als ein Unterfangen heraus, dem nicht auf normalen wissenschaftlichen Recherchewegen nachgegangen werden konnte. In den wissenschaftlichen Datenbanken fand sich damals eine sehr überschaubare Anzahl an Einträgen über Demenz und Mehrsprachigkeit allgemein, noch weniger, wenn man die Institution Pflegeheim hinzunahm, und schon gar keine mehr, wenn man es auf Russisch oder eine andere slavische Sprache begrenzte. Ähnlich schwierig zeigt es sich, verlässliche Zahlen von betroffenen Personen zu erhalten. Hier stellt sich das Hindernis von zwei Seiten: Weder Sprache noch Pflegebedürftigkeit bzw. deren Ursache werden statistisch erhoben.

Soviel zum Stand der Wissenschaft im Jahr 2016 - der kleine Ausschnitt aus der Praxis sprach jedoch seine so eindrückliche Sprache, dass sich ein weiterer Gedankengang anschloss: Wo sich eine betroffene Person mit einem solchen sprachlichen Schicksal findet, findet sich sicher mindestens eine zweite. Setzt man dies fort, ergibt sich die Schlussfolgerung, dass es eine wachsende Anzahl an mehrsprachigen Personen in Deutschland gibt, die sich ihr Leben lang in einer gelebten Mehrsprachigkeit bewegten und mit dem Eintritt in die Pflegebedürftigkeit und dem Einzug in ein Pflegeheim diese aufgeben und in einer deutsch-dominierten Sprachumgebung leben müssen. Damit ergibt sich für diese Menschen nicht nur der bekanntermaßen belastende Wechsel der vertrauten Wohnumgebung, sondern auch der vertrauten Sprachheimat. Und was der Verlust der Sprache bedeutet, kann wohl jeder Mensch, der einmal im Ausland gewesen ist, nachempfinden. Was er jedoch auch noch unter Krankheitsbedingungen bedeuten mag, bei denen sprachliche Fähigkeiten schrittweise verloren gehen, erscheint doppelt dramatisch. Eine solche eindrucksvolle Erkenntnis tritt in einem wissenschaftlichen Leben selten ein, doppelt schwer wiegt sie dann auch noch, wenn dies einer Linguistin klar wird - die überragende Macht der Sprache und die Tragik ihres Verlustes können kaum offensichtlicher werden.

Was aber kann nun die Wissenschaft tun, um ein solches, in der Praxis offensichtlich bestehendes Problem zu lindern? Die Wissenschaft kann natürlich zunächst beschreibend tätig werden und für eine Sichtbarkeit der Lage sorgen, 
daneben kann sie jedoch auch durch ihre Verankerung an der Institution Universität und der damit verbundenen Lehre neue Wege einschlagen. Warum sollte die Wissenschaft nicht versuchen, aus ihrem sprichwörtlichen Elfenbeinturm herauszutreten und Sprache in die Welt zu tragen? Die Vision, Brücken zwischen Institutionen, Generationen, Menschen und Sprachen zu bauen, stand Pate bei der Entwicklung des Projektes UnVergessen. Im Kern steht die Idee, Studierende der Universität mit russischem oder polnischem sprachlichen Hintergrund mit entsprechenden russisch- oder polnischsprachigen Pflegebedürftigen in Pflegeheimen zusammenzubringen. Diese Vision konnte mit finanzieller Unterstützung der Robert Bosch Stiftung im Rahmen der „Werkstatt Vielfalt“ erstmalig im Winter 2016 umgesetzt werden. Es fand sich eine interessierte Studierendengruppe, die als Pioniere in drei Bochumer Pflegeheimen auf Pflegebedürftige trafen und sie für die Dauer von acht Monaten wöchentlich besuchten. Sie waren jeweils einer festen Person mit gleichem sprachlichen Hintergrund zugeordnet und verbrachten mit ihr gemeinsame Zeit, während der die pflegebedürftige Person ungeteilte Aufmerksamkeit und vor allem die z. T. einzige Gelegenheit bekam, in ihrer Erstsprache zu kommunizieren. Die Betreuungsarbeit der Studierenden wurde dabei durch mich als Projektleiterin vorbereitet, intensiv begleitet und aufgearbeitet.

Der erste Durchlauf stand im Zeichen eines explorativen Feldzuganges. Es mussten in allen beteiligten Bereichen interessierte Projektteilnehmer/innen und Kooperationspartner/innen gefunden und diese erstmalig miteinander in Kontakt gebracht werden. Durch die universitäre Verankerung am Institut für Slavistik kam der Kontakt zu Studierenden mit slavischsprachigem Hintergrund zustande, ein Kooperationspartner an der Hochschule für Gesundheit - der Hochschullehrer André Posenau - vermittelte Ansprechpartner in Pflegeheimen rund um Bochum. Nachdem der erste und bis heute mit zwei Einrichtungen im Projekt vertretene Kooperationspartner auf überregionaler Ebene (das Evangelische Johanneswerk) sowie ein Bochumer Heim (St. Marienstift) aus studentischer Initiative gewonnen werden konnten, sprach sich das Angebot unter den Pflegeheimen herum, sodass ein weiterer Kooperationspartner (die Einrichtung „Glockengarten“ der $\mathrm{SBO} /$ Senioreneinrichtungen Bochum $\mathrm{gGmbH}$ ) von sich aus die Teilnahme am Projekt initiierte. So startete das Projekt mit drei beteiligten Pflegeheimen, in denen insgesamt sieben russisch- und polnischsprachige Bewohner/innen lebten, für die eine Teilnahme am Projekt infrage kam. Auf studentischer Seite kam eine Gruppe von sieben Studierenden zusammen, die sehr gute (meist muttersprachliche) Kenntnisse im Polnischen und Russischen mitbrachten und unterschiedliche Studiengänge besuchten (Slavische Philologie, Russische Kultur und Geschichte). Das Studienangebot in Form eines zweisemestrigen Moduls wurde in den (für Studierende vieler Fakultäten offenen) Optionalbereich eingespeist und mit 10 
CP für die gesamte Laufzeit vergütet. Die Studierenden besuchten über einen mehrmonatigen Zeitraum (von Januar bis August) einen ihnen fest zugeordneten pflegebedürftigen Menschen und tauschten sich mit ihm in seiner Muttersprache aus. Im Laufe der Monate knüpften alle Teilnehmer/innen ein enges Band. Die Studierenden berichteten in den wöchentlichen Austauschtreffen von vielen bewegenden Momenten und unterstrichen dabei vor allem immer wieder, als wie wichtig es empfunden wird, den Pflegebedürftigen die Möglichkeit zu geben, in ihrer vertrauten Sprache zu sprechen. Die Auswirkungen dieser sprachlichen Begleitung konnten dabei nicht nur die Studierenden beobachten, auch unsere Ansprechpartner in den kooperierenden Pflegeheimen berichteten in Austauschtreffen über verblüffende Veränderungen bei den begleiteten Personen. Zugleich stellte sich immer mehr heraus, dass auch die Studierenden durch den Austausch mit einer anderen Generation, mit ihrem Erfahrungsschatz und anderem Blick auf das Leben eine Bereicherung erfuhren, die sich mit wenig anderen Erfahrungen vergleichen lässt. Die Studierenden sammelten diverse Eindrücke, die sie in den Begleittreffen teilten. Über das gemeinsame Sprechen und Diskutieren entstand ein immer reicheres Bild von der Situation mehrsprachiger Pflegebedürftiger, das auf eine solche Weise noch nirgendwo festgehalten und beschrieben wurde.

Nach Beendigung der ersten Projektrunde stand bei allen Beteiligten fest, dass dieses Projekt mit der dort erlebten sozialen Erfahrung und dem Eindruck der Kraft der Erstsprache fortgesetzt werden muss. Und so startete UnVergessen nun auch mit einem eigenen, von einer Teilnehmerin entworfenen Logo - in das zweite Jahr (Abb. 1).

\section{Die Weiterentwicklung des Projektes ${ }^{2}$}

Vor den mehr als positiven Erfahrungen des ersten Durchlaufes wurde das Projekt im zweiten Jahr - zunächst ohne finanzielle Förderung - ab Wintersemester 2017/2018 fortgeführt. Dabei wuchs es in der Anzahl an Kooperationspartnern (auf sieben), an teilnehmenden Pflegebedürftigen (auf 10) und an Studierenden (auf acht) an. Im weiteren Verlauf offenbarten sich immer mehr die Potenziale der Betreuungsarbeit. Darunter fallen nicht nur die Auswirkungen auf die Pflegebedürftigen, der zu beobachtende Zuwachs an sozialer Kompetenz bei den Studierenden, eine Annäherung der Generationen oder die Sensibilisierung für die Situation in Pflegeheimen, sondern nicht zuletzt auch die Erkenntnis, dass

\footnotetext{
${ }^{2}$ Auch in diesen Abschnitt wurden Textteile aus Karl und Behrens (2020) integriert. Diese stammen aus meiner Autorenschaft, für die Erlaubnis der Wiederverwendung vgl. Fußnote 1.
} 
Abb. 1 Logo von UnVergessen

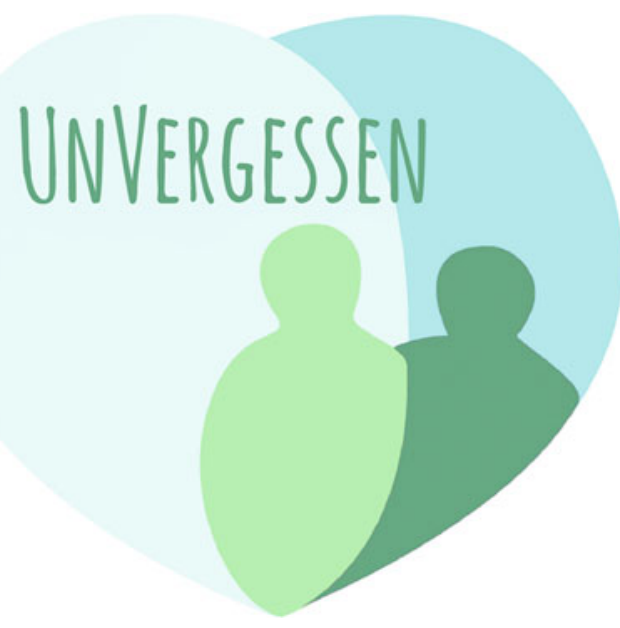

es in diesem speziellen Bereich an Grundlagenforschung mangelt und sich so eine Vielzahl an potenziellen wissenschaftlichen Fragestellungen ergibt. Diese Erkenntnis leitete sodann den zweiten Durchlauf und führte dazu, dass sich Studierende aus der Teilnahme am praktischen Projekt heraus in wissenschaftlicher Weise mit dem Themengebiet befassten und ihre Abschlussarbeiten dazu schrieben. So entstanden eine Bachelor- und eine Masterarbeit in diesem Zeitraum, parallel dazu entschied sich eine Teilnehmerin der ersten Runde, ihre Dissertation in diesem Feld anzusiedeln. Dies leitete dazu über, das Projekt in eine forschungsorientierte Richtung zu lenken und für den dritten Durchlauf unter dem Fokus des Forschenden Lernens neu auszurichten. Im Rahmen der Förderung von inSTUDIES ${ }^{\text {PLUS }}$ (seinerseits gefördert vom Bundesministerium für Bildung und Forschung, FKZ: 01PL16072) in der Projektlinie Forschendes Lernen ${ }^{3}$ ab Juli 2018 (bis Ende Juni 2019) wurde UnVergessen zu UnVergessen ${ }^{\text {PLUS }}$. Der entsprechende dritte Durchlauf (Wintersemester 2018/2019 - Sommersemester 2019) stand unter dem Stern der Ausarbeitung studentischer wissenschaftlicher Arbeiten vor dem Hintergrund ihrer praktischen, insbesondere sprachlichen Betreuungsarbeit. Dabei wurde vieles von der Konzeption beibehalten. Auch UnVergessen PLUS ist ein zweisemestriges Modul, das aus insgesamt drei Teilen besteht: einem Vorbereitungsseminar, der sprachlichen Betreuungsarbeit und einem Reflexionsseminar. Es ist curricular in mehr Bereiche eingebunden, als es vorher der Fall war. So können Studierende weiterhin auf Bachelor-Ebene über die Einspeisung des Moduls in den Optionalbereich teilnehmen, auf Master-Ebene wird die Teilnahme 
über die Verankerung im Ergänzungsbereich ermöglicht. Daneben ist für Studierende des Studienganges Empirische Mehrsprachigkeitsforschung die Teilnahme als Praktikum anrechenbar.

Im Durchlauf von Wintersemester 2018/2019 bis Sommersemester 2019 nahmen zehn russisch- und polnischsprachige Studierende mit unterschiedlichen Studiengängen und -phasen teil. In insgesamt neun kooperierenden Pflegeheimen besuchten sie von Januar bis August 2019 elf russisch- und polnischsprachige Pflegebedürftige (Abb. 2).

$\mathrm{Zu}$ diesem Zeitpunkt blickte das Projekt bereits auf vielfältige Erfahrungen und Weiterentwicklungen zurück. Es hatte sich universitär etabliert und ein stabiles Grundgerüst aufgebaut. Es war curricular verankert und begleitete die teilnehmenden Studierenden über deren gesamte Teilnahmedauer am Projekt. Dieses Grundgerüst hat sich für den vierten Durchlauf stark bewährt. Dieser startete mit Beginn des Wintersemesters 2019 hoffnungsfroh und mit einer Gruppe von elf motivierten Studentinnen. Sie deckten dabei neben Russisch (sieben) und Polnisch (zwei) auch Chinesisch und Spanisch ab und konnten mit Ende des Jahres in die Pflegeheime an entsprechend gleichsprachige Pflegebedürftige vermittelt werden

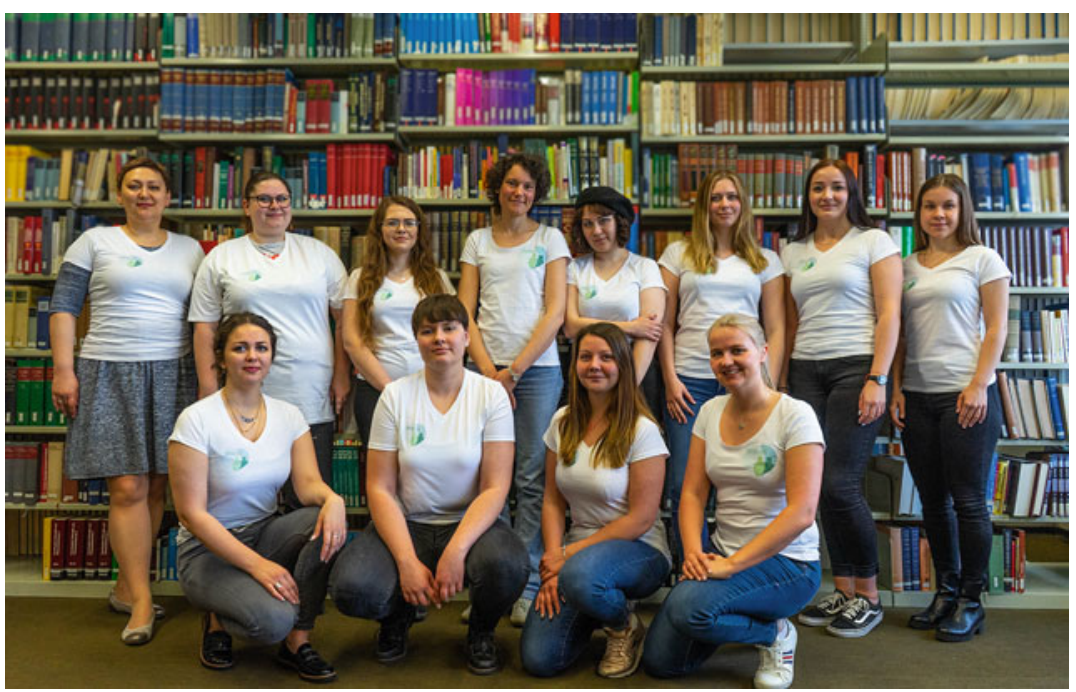

Abb. 2 Gruppenfoto der Teilnehmerinnen an UnVergessen ${ }^{\text {PLUS }}$ mit Projektleiterin und wiss. Mitarbeiterin im Frühjahr 2019, Foto R. Müller 
und ihre Besuche starten. Allerdings war diese Projektrunde schon sehr bald darauf besonderen Herausforderungen ausgesetzt. Im Frühjahr 2020 waren auch für die Projektteilnehmerinnen wegen der Corona-Pandemie keinerlei Besuche in den Pflegeheimen mehr möglich - ein schnelles und kreatives Umdenken war erfordert, auf das ich näher im Abschnitt „Das Projekt zu Zeiten von Corona“ eingehe. Dass dies überhaupt möglich war, war nicht zuletzt dem so stabilen Netzwerk und den vorherigen positiven Erfahrungen zu verdanken. Und so konnte - wenn auch unter komplett anderen Bedingungen - diese Gruppe das Projekt fortsetzen und ihre sehr besonderen Erfahrungen sammeln. Diese hat sie mittlerweile an eine neue Gruppe übergeben, die sich trotz der anhaltenden Beschränkungen und Unsicherheiten gefunden hat und hochmotiviert ist, in Kontakt zu Pflegebedürftigen zu treten. Die Gruppe des Jahres 2020/2021 besteht aus acht Student/innen. Neben Russisch und Polnisch ist in diesem Jahr auch Finnisch vertreten. Erfreulicherweise konnte bereits zu Ende des Jahres 2020 die finnischsprachige Studentin einen ersten Kontakt zu einer finnischsprachigen Frau aufnehmen, die anderen Teilnehmerinnen warten zum Zeitpunkt der Drucklegung des Buches auf den Erstkontakt, sind aber bereits den Pflegeheimen zugeordnet. Zugleich deutet sich am Horizont mit der Impfmöglichkeit und der Fokussierung auf die Versorgung in den Pflegeheimen ein Hoffnungsschimmer ab, dass vielleicht doch in naher Zukunft Besuche im alten Maßstab wieder möglich sind und die studentischen Teilnehmerinnen dieses Jahres den bewährten Weg gehen können.

\section{Projektablauf, Forschendes Lernen und Netzwerke ${ }^{3}$}

Der Einstieg in die Projektarbeit findet im Wintersemester in Form eines universitären, wöchentlich stattfindenden Seminares statt, dessen Ziel es ist, eine wissenschaftliche, soziale und kommunikative Grundlage als Vorbereitung für die avisierte Betreuungsarbeit zu schaffen. Durch die Lektüre und Besprechung wissenschaftlicher Grundlagentexte wird ein elementares Wissen in den thematisch relevanten Bereichen vermittelt: Konzepte und Vorstellung vom Alter(n); zentrale

\footnotetext{
${ }^{3}$ Auch in diesem Abschnitt finden sich Textteile aus Karl und Behrens (2020). Diese stammen aus meiner Autorenschaft. für die Erlaubnis der Wiederverwendung vgl. Fußnote 1.

Weitere Eindrücke von den Projektrunden und den Ergebnissen finden sich unter der Projekthomepage: www.un-vergessen.de auf der Unterseite „Berichterstattung“ (https:// www.un-vergessen.de/berichterstattung). Hier sind, neben Stimmen aus der Presse über das Projekt, auch studentische Berichte aus den ersten Runden sowie eine Dokumentation der Posterausstellung von $2019 \mathrm{zu}$ finden.
} 
Erkrankungen des Alter(n)s wie (vor allem) Demenz; Sprache und Kommunikation (inkl. entsprechender Strategien) im Pflegeheim sowie die Entwicklung von Mehrsprachigkeit und die Stellung der Sprachen im Laufe des Lebens. Im weiteren Verlauf wird der Bogen zur praktischen Anwendung geschlagen. Nach der Zuordnung der studentischen Teilnehmer/innen zu den Pflegebedürftigen erfolgt eine gezielte Vorbereitung auf die Betreuungsarbeit. Dies geschieht exemplarisch etwa durch die Simulation von ausgewählten Kommunikationssituationen und die Suche nach unterschiedlichen Möglichkeiten, womöglich auftretende (kommunikative) Probleme zu lösen. Hier findet neben der gemeinsamen Vorbereitung im Seminar eine Beratung und Betreuung durch Teilnehmer/innen der vorherigen Durchgänge von UnVergessen statt. In Einzeltreffen wird so eine Peer-to-PeerBegleitung ermöglicht, in der die Studierenden der letzten Jahre ihre Erfahrungen teilen. In dieser Weise erfolgt - bei Teilnahme der gleichen Pflegebedürftigen in der Folgerunde - eine Art „Übergabe“ zwischen den studentischen Teilnehmer/innen. In solch einem Fall finden die ersten Besuche des Pflegebedürftigen gemeinsam mit dem/der Teilnehmenden der vorherigen und der neuen Runde statt.

Der zweite Modulteil umfasst die Betreuung und die sprachlich-soziale Arbeit in den Pflegeheimen. Vorgesehen ist der regelmäßige Besuch (ca. eine Stunde pro Woche) eines Pflegebedürftigen durch jeweils eine/n Studierende/n über den Zeitraum von ca. neun Monaten. Die Ausgestaltung der Besuche hängt von den Fähigkeiten und Bedürfnissen der/des konkreten Pflegebedürftigen und den Interessen der/des Studierenden ab. Sie kann von Alltagskommunikation in der gemeinsamen Sprache, dem Schauen von Filmen oder dem Vorlesen von Büchern (Zeitschriften, Zeitungen etc.) über gemeinsames Singen bis hin zur Begleitung auf Spaziergängen inklusive von Erkundungen der näheren Umgebung reichen. In diesem Teil des Moduls - das im Laufe der Vorlesungszeit im Wintersemester beginnt und sich dann bis zum Ende des Sommersemesters erstreckt - steht der Aufbau einer persönlichen Beziehung zwischen den beiden Tandempartner/innen im Vordergrund. Studierende und Pflegebedürftige sollen sich kennenlernen, die individuellen Besonderheiten (und auch Einschränkungen) wahrnehmen und vor diesem Hintergrund die gemeinsamen Aktivitäten planen. Die Studierenden erlangen hier Einblicke in den Pflegealltag, lernen einen pflegebedürftigen Menschen mit seinen körperlichen und/oder kognitiven Einschränkungen kennen und entwickeln ein Gespür für dessen Besonderheiten und Bedürfnisse.

Vor diesem Erfahrungshintergrund kann im dritten Modulteil das eigenständige Forschende Lernen verfolgt werden. Die Studierenden sollen basierend auf ihren Kenntnissen aus ihren studierten Fächern und unter Einbeziehung der Rahmenbedingungen ihres Projektpartners aus ihrem eigenen Interesse heraus eine Fragestellung formulieren, der sie im Laufe des Sommersemesters nachgehen. 
Diese kann in unterschiedlichen Disziplinen verankert sein, soll aber zum allgemeinen Themenbereich von UnVergessen passen. Die Forschungsthemen zeigen, wie vielfältig die studentischen Interessen liegen und auf welch bereichernde Art diese das breite Spektrum des Projektes abbilden. Es lassen sich Arbeiten finden, die schwerpunktmäßig (kern)linguistische Themen betrachten, wie z. B. die Frage, ob unter Demenz eine Beeinträchtigung der Aspektverwendung im Russischen zu beobachten ist. Daneben beschäftigen sich einige Arbeiten mit der Beschreibung bzw. Auswirkung von unterschiedlichen Gesprächsstrategien im Umgang mit Demenzpatienten, zum Teil mit Fokus auf die Kommunikation zwischen einem mehrsprachigen Bewohner und seinem (deutschsprachigen) Pflegepersonal. Eine Studentin greift die (therapeutische) Wirkung von Musik auf und untersucht, in welcher Weise die Melodie bekannter russischer Volkslieder Einfluss auf die Erinnerungsfähigkeit haben kann. Eine vierte Reihe von Arbeiten ist im Bereich der Erforschung von biografisch-historischen, kulturellen und sozialen (intergenerationellen) Aspekten zu verorten. So ging eine Teilnehmerin der Frage nach, welche unterschiedlichen Konzepte von Heimat bei Vertretern verschiedener Generationen von ehemaligen Sowjetbürgern zu beschreiben sind. Eine weitere fokussierte sich auf eine introspektive Reflexion des Verhältnisses zwischen ihr als Vertreterin der jungen Generation zu Vertretern der alten Generation mit Hinblick darauf, inwiefern sich ihre Erfahrungen aus dem Projekt darauf auswirken.

Im Laufe des Seminares, das auch im Sommersemester in wöchentlichen Treffen stattfindet, wird im engen Austausch mit allen Teilnehmenden eine geeignete Methode für die jeweilige Forschungsfrage gesucht und ein entsprechendes Forschungsdesign erstellt. Dieses wird im Laufe des Sommersemesters umgesetzt und in seinen einzelnen Schritten im Seminar besprochen. Hierbei folgt das Seminar dem logischen Ablauf von Arbeiten im Bereich des Forschenden Lernens: Nach und während fortlaufender Sichtung der entsprechenden Forschung im Themenbereich erfolgt die Formulierung der Fragestellung, der sich die geeignete Methodenwahl anschließt. Die Ausformulierung des Forschungsdesigns und die exemplarische Erprobung stehen als Folgeschritte an, ebenso wie die (zunächst ebenfalls exemplarische) Auswertung und Konstruktion der Ergebnisse. Als letztes wird die Diskussion der Ergebnisse und die abschließende und umfassende Reflexion des gesamten Prozesses mit seinen Problemen, Lösungen und Perspektiven unternommen. Diese Schritte werden begleitet von entsprechenden Schreib- und Präsentieraufgaben (Zusammenfassung des Forschungsstandes und Formulierung der o.g. Schritte) sowie ihrer gemeinsamen, feedbackorientierten Besprechung im Seminar. So kann der Prozess des Forschenden Lernens unterstützt und reflektiert werden, zugleich dienen die Schreibaufgaben der Erstellung 
des schriftlichen Endberichtes. Neben diesem erarbeitet die gesamte Gruppe eine weitere Form der Darstellung ihrer geleisteten Arbeit, wobei beide Facetten - die sprachlich-soziale Betreuungsarbeit und die eigene wissenschaftliche Forschung - gleichermaßen berücksichtigt werden sollen. Im dritten Durchlauf geschah dies bspw. in Form einer Posterausstellung, in der anhand von insgesamt zehn Postern das Projektgeschehen visualisiert und einer breiteren Öffentlichkeit präsentiert wurden.

Nach insgesamt zwei Semestern endet die Teilnahme am Projekt und eine neue Runde an Studierenden formiert sich. Bei der Übergabe an die neuen Studierenden steht der Wunsch im Zentrum, die bisher in den Pflegeheimen betreuten Personen auch in der Folgerunde weiter zu begleiten. Dies ist in vielen Fällen gelungen, weshalb eine Reihe an Personen bereits im vierten bzw. bald im fünften Jahr von UnVergessen begleitet wird. Hier findet ein enger Austausch zwischen den jeweiligen Studierenden statt, die dieselbe Person besuchen. Auf diese Weise wird auch hier eine besondere Verbindung ermöglicht: Die ,,alten“ stehen den „,neuen“ UnVergessen-Teilnehmer/innen als Mentor/innen zur Seite und unterstützen sie. Aus dieser Mentorenidee ist im Lauf des letzten Jahres ein neues Netzwerk entstanden: Es haben sich Alumni aus allen ehemaligen Projektrunden gefunden, die sich untereinander vernetzen und über die aktive Teilnahme am Projekt hinaus in Kontakt stehen. Sie tauschen sich über Neuigkeiten rund um das Themengebiet aus, treffen sich zu gemeinsamen Kinoabenden (z. B. zum Start des Filmes „Romys Salon") und pflegen damit eine besondere Beziehung. Daneben ist aus diesem Alumni-Netzwerk die Initiative entstanden, regelmäßige Sprechstunden für die aktuellen Projektteilnehmer/innen anzubieten. Hier finden sich jeweils wechselnd ehemalige Teilnehmer/innen und stehen in einem festen Zeitraum den aktuellen mit Rat und Tat zur Seite. Dieses Angebot wird sehr gerne angenommen, da es hier studentische Ansprechpartner gibt, die selbst die Erfahrungen gemacht haben und sich in einer vergleichbaren Situation befanden, wie sie selbst momentan. Der unmittelbare Austausch auf Augenhöhe wird dabei sehr geschätzt.

Mit einem Teil dieser sehr engagierten Gruppe an Alumni konnte dabei die bereits länger angedachte Arbeit an einem Sammelband rund um das Projekt umgesetzt werden. Mit ihrem freiwilligen Engagement war es möglich, Beiträge rund um ihre Arbeit und das Projekt zu erstellen und hier in dieser Form der Öffentlichkeit zu zeigen.

So lässt sich also sagen, dass durch das Projekt vielfältige Möglichkeiten erwachsen sind, Brücken zu bauen. Dabei sind die Projektteilnehmer/innen und Alumni in unterschiedlicher Weise Multiplikatoren, die für das Thema und die hier betroffene vulnerable Gruppe an Personen in der Öffentlichkeit sensibilisieren. 


\section{Das Projekt zu Zeiten von Corona}

Im Wintersemester 2019/2020 startete die vierte Runde von UnVergessen und beschritt, wie oben ausgeführt, den bereits erprobten Weg des Projektes. Dabei fand sich eine Gruppe von elf Studentinnen, die motiviert und mit Unterstützung des neues Alumni-Netzwerkes und ihren Mentor/innen in das Projekt starteten. Im Verlauf des Wintersemesters fand die theoretische Vorbereitung statt, während der parallel die Zuordnungen zu den Pflegeheimen und -bewohner/innen organisiert wurden. Auch in diesem Jahr wurde dabei primär darauf geachtet, bereits bestehende Kooperationen und die Begleitung von Bewohner/innen aus den vorherigen Jahren fortzuführen. Und so konnten zehn Pflegebedürftige vermittelt werden, die in sieben Einrichtungen in und um Bochum leben. Dabei wurde erstmals Spanisch als weitere Sprache in das Projekt aufgenommen, sowie die Begleitung eines chinesischen Pflegebedürftigen gezielt ausgebaut. Zum Ende des Jahres 2019 waren alle Teilnehmerinnen vermittelt und starteten ihre regelmäßigen Besuche in den Einrichtungen. Dabei zeigte sich sehr bald, wie harmonisch und homogen sich diese Projektrunde entwickelte. Durch das ausgebaute Netzwerk und damit den engen Kontakt zu den Ehemaligen entstanden sehr schnell ein familiäres Miteinander und ein sehr befruchtender gemeinsamer Austausch. Dies zeigte sich z. B. in der spontanen Frage einer Teilnehmerin, welche Möglichkeiten es für sie gäbe, auch nach Ablauf ihrer Teilnahme die Besuche bei ihrem Bewohner und ihre Aktivität im Projekt fortzusetzen. Es reihten sich viele Berichte vonseiten der Studentinnen über den schnell hergestellten und sehr freundschaftlichen Kontakt zu ihren Bewohner/innen. Mit Ende des Wintersemesters setzten die Studentinnen ihre Besuche in den Einrichtungen fort. In zwei anberaumten (freiwilligen) Gruppentreffen zwischen den Vorlesungszeiträumen berichteten sie auch hier von vielen schönen, nachdenklichen und $\mathrm{z}$. T. auch wehmütigen Erlebnissen, über die gemeinsam reflektiert wurde. Alle machten sich langsam (z. T. auch schon sehr konkret) auf die Suche nach möglichen Themen für ihre forschenden Ausarbeitungen, die im Lauf des Sommersemesters angestanden hätten. Zeitgleich dazu spitzte sich jedoch die gesundheitliche Pandemie-Situation zu. Mitte März kam dann die für alle Beteiligten einschneidende Nachricht, dass ab sofort keine Besuche in Pflegeeinrichtungen mehr möglich sind. Dies traf die Studentinnen sehr hart, zugleich zeigte sich jedoch in dieser Ausnahmesituation der Zusammenhalt im Projekt und der Gruppe. Schnell stand fest, dass es nicht infrage kam, das Projekt abzubrechen und damit die Kontakte einfach während dieser schweren Zeit der Isolation auszusetzen und danach evtl. neu zu beginnen. Es war allen klar, dass in irgendeiner Weise der Kontakt gehalten werden soll. Da sich jedoch zugleich die Situation in den Pflegeheimen dramatisch zuspitzte, Abläufe unklar 
und Ansprechpartner über Gebühr eingespannt waren, stand es ebenso fest, dass wir für keine Mehrarbeit aufseiten der Einrichtungen sorgen wollten.

Auf der Suche nach Handlungsoptionen verfielen wir auf zwei kurzfristig umzusetzende Möglichkeiten: telefonischer Kontakt oder Briefe.

Der telefonische Kontakt hat den Vorteil, dass der an sich im Projekt angelegte Gedanke des direkten Austausches fortgesetzt werden kann, jedoch hat er zugleich zwei sehr große Nachteile: zum einen ist es keinesfalls so, dass jede/r Bewohner/in über ein eigenes Telefon verfügt und einfach angerufen werden kann. In vielen Fällen hat die Station einen Anschluss, über den die jeweiligen Bewohner/innen kontaktiert werden können. In diesen Fällen bedeutet also der telefonische Kontakt, dass jeweils eine Pflegekraft eingebunden werden müsste. In einigen Einrichtungen ist dies nach vorheriger Absprache ermöglicht worden. So hält z. B. eine Studentin wöchentlichen Kontakt über das Telefon mit ihrer Bewohnerin. In anderen Fällen ist es jedoch aus Kapazitätsgründen nicht möglich, dies umzusetzen. Der zweite Nachteil liegt darin, dass Telefonate und reale mündliche Gespräche nicht miteinander zu vergleichen sind und gerade bei Menschen, die an Demenz erkrankt sind, einen sehr großen Unterschied machen. Im direkten Gespräch kann die nonverbale Kommunikation Verständnisprobleme auflösen und manchmal sogar nicht bemerkbar machen, Gesprächspausen werden nicht immer als unangenehm empfunden und gemeinsame Aktivitäten, wie z. B. Kartenspielen oder Spazierengehen sind überhaupt erst möglich. Beim Telefonat hingegen sind die Kommunikationspartner auf das gesprochene Wort angewiesen, begleitende Gestik und Mimik entfallen, die Stimme erscheint unter Umständen leiser. All dies sind Dinge, die für einen kognitiv beeinträchtigten Menschen weitaus schwerer ins Gewicht fallen als für gesunde Personen. Hinzu kommt häufig ein schlechteres Gehör. Somit kann ein Telefongespräch für einige unserer Pflegebedürftigen eine so große Herausforderung sein, dass man ihm damit eher mehr Schwierigkeiten bereitet als Freude.

Die andere Möglichkeit, die sich bot, ist die, seiner/m Tandempartner/in Briefe und andere postalische Grüße zu schicken. So wurden die Studentinnen aufgefordert, kreativ zu werden und nach Möglichkeiten zu suchen, ihren Bewohner/innen mit kleinen Grüßen, gebastelten und gemalten Dingen oder anderen kleinen Aufmerksamkeiten etwas Freude zu schicken. Da Ostern vor der Tür stand, boten sich hier viele Möglichkeiten, die durchaus ansprechend genutzt wurden. Alle Teilnehmerinnen verfassten Briefe, schickten z. T. auch Pakete oder ließen ihrer Person Blumensträuße schicken. Auch hierbei galt es, einige Schwierigkeiten zu bedenken: Die von uns begleiteten Pflegebedürftigen sind z. T. recht stark kognitiv eingeschränkt und dadurch nicht mehr in der Lage, selbstständig zu lesen, 
geschweige denn zu schreiben. Daher mussten Wege gefunden werden sicherzustellen, dass die Grüße auch bei der Person ankommen. Einige Teilnehmerinnen haben dies so gelöst, dass sie die Grüße in der jeweiligen Sprache der Bewohner/innen geschrieben haben und zusätzlich noch einmal übersetzt haben, damit eine Pflegekraft im Zweifel die Grüße vorlesen kann. Auf diese Weise war es allen Studentinnen möglich, ihren Personen Grüße zu schicken und zumindest so aus der Ferne zu zeigen, dass sie auch weiterhin an sie denken.

Um einen kleinen Eindruck von den Aktivitäten zu geben, sind hier Grüße von zwei Studentinnen abgebildet, die sie an ihre Personen im Pflegeheim geschickt haben. Der erste auf Russisch abgedruckte Brief wurde von der Studentin selbst ins Deutsche übersetzt (Abb. 3 und 4, Abb. 5 zeigt ihre Geschenke), die beiden Abb. 6 und 7 wurden nur auf Russisch verschickt und hier im Anschluss übersetzt (Abb. 3, 4 und 5).

Übersetzung:

Abb. 3 Russischer Brief von Nina Heck, Teilnehmerin von UnVergessen, an eine an Demenz erkrankte Bewohnerin

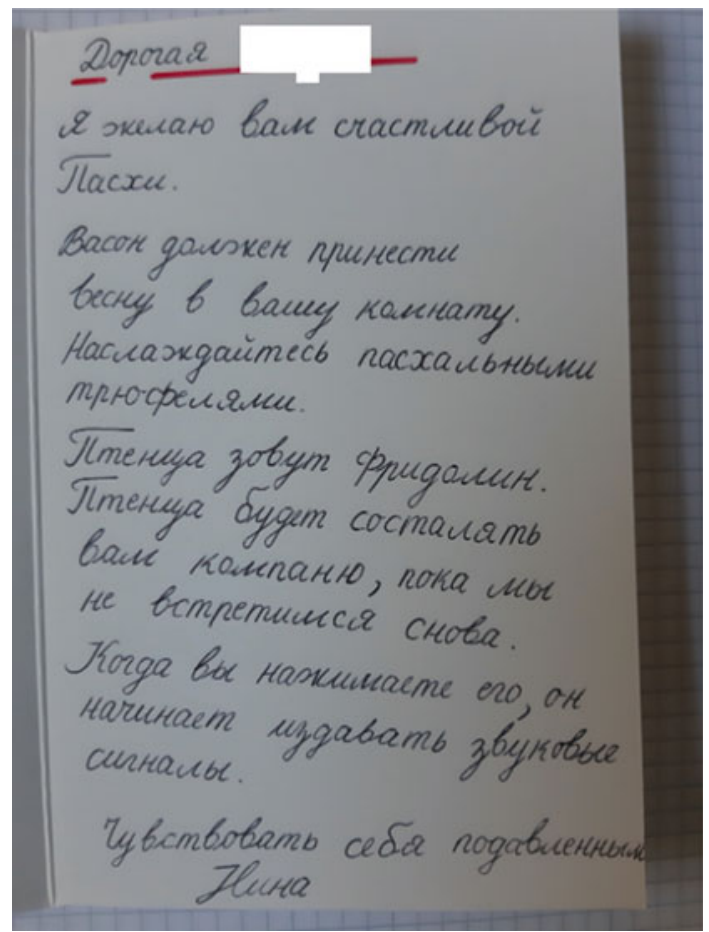


Abb. 4 Übersetzter Brief ins Deutsche von Nina Heck, Teilnehmerin von UnVergessen, an eine an Demenz erkrankte Bewohnerin

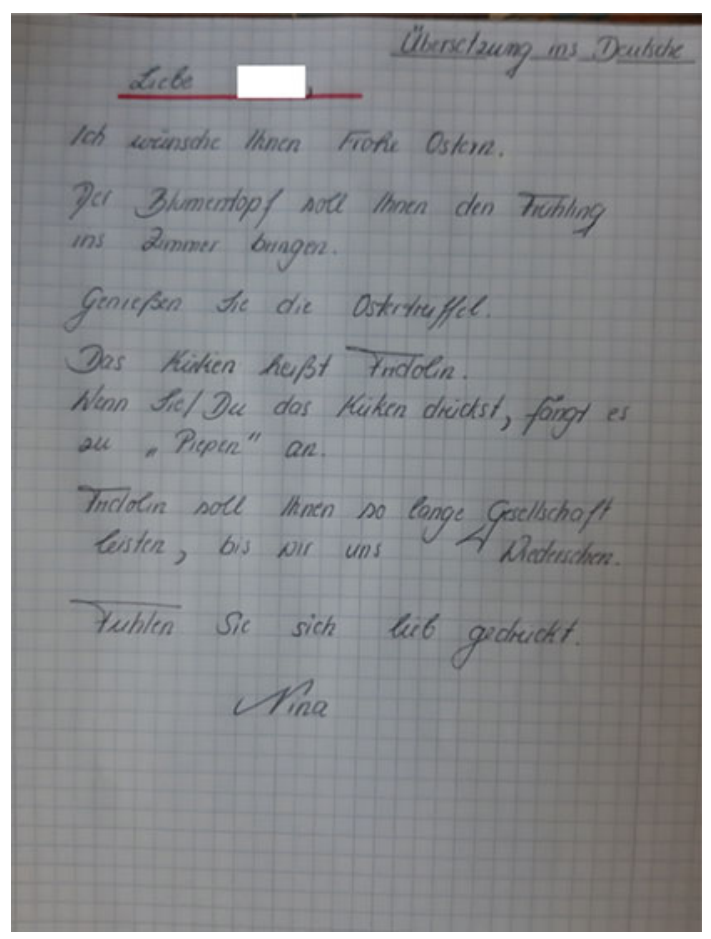

Lieber XXX! Ich hoffe, Sie haben das Bild von der Zigeunerin ${ }^{4}$ erhalten. Sie mögen dieses Lied so gerne, dass ich beschloss, Ihnen eine Freude zu machen und dieses Bild für Sie zu malen. Iuliia

Das auf der Zeichnung abgebildete Gedicht ist eine Strophe aus dem Lied von Надежда Кадышева / Nadeža Kadyševa „Шыганочка“ / „Cyganočka“ ,Die Zigeunerin“. Dieses Lied hat Iuliia Rzhevkina mit ihrem Bewohner regelmäßig gehört und gesungen. Um an diese gemeinsame Aktivität zu erinnern und ihm eine besondere Freude zu machen, hat sie das Lied und die in der Strophe beschriebenen Merkmale künstlerisch ins Bild übersetzt. In der Strophe wird geschildert, dass eine Frau einen Zigeuner heiraten und mit dem Schal um die Schultern und

\footnotetext{
${ }^{4}$ Ich möchte hier anmerken, dass es sich dabei um ein gleichsprachiges russisches Lied handelt, in dem diese Lexik so verwendet und deswegen hier und auch im folgenden Text übernommen wird.
} 


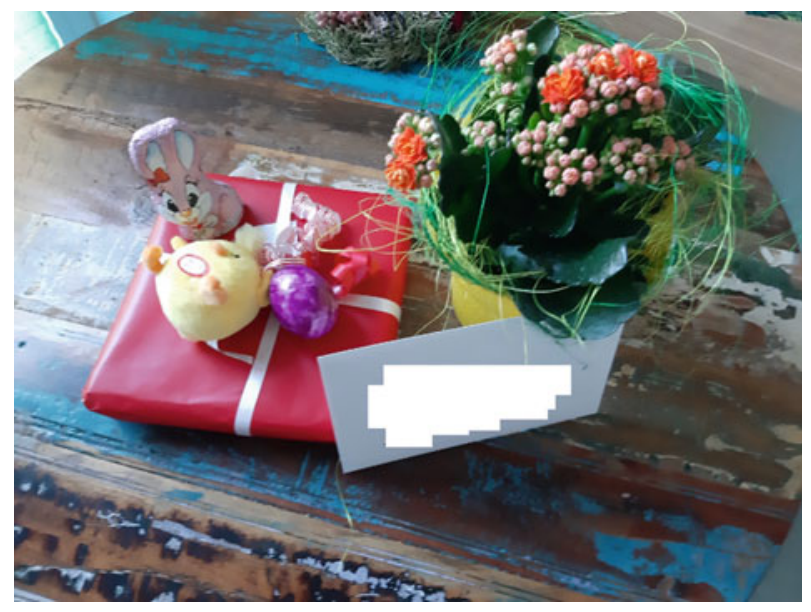

Abb. 5 Foto von der Karte und den Geschenken von Nina Heck, Teilnehmerin von UnVergessen, an eine an Demenz erkrankte Bewohnerin

den Karten in der Hand unter die Gaukler gehen möchte. Diesen persönlichen Gruß hat Iuliia ins Pflegeheim gebracht und ihrem Bewohner überbringen lassen.

Diese Impressionen stehen stellvertretend für die zahlreichen Grüße, Bilder und Aufmerksamkeiten, die auch in der Zeit des Besuchsverbots von den Teilnehmerinnen in die Pflegeheime gesandt wurden. In vielen Fällen fanden Kombinationen aus Telefonaten und Briefen statt, in einem Fall wurde sogar ein regelmäßiger Video-Chat ermöglicht. Alle Teilnehmerinnen sind aktiv geworden und haben den für sich selbst und ihre/n Tandempartner/in besten Weg gefunden, in Kontakt zu bleiben oder wenigstens Grüße zu senden. Eine Teilnehmerin berichtete dabei sogar, dass ihre Person (an Demenz erkrankt) über das Telefon unerwartet viel spricht. An manchen Tagen sogar mehr als in direkten Gesprächen. Dies überraschte (aus oben ausgeführten Gründen) sehr, war aber ein erhellender Moment, da sich darin zeigt, dass das Verhalten von an Demenz erkrankten Personen nicht vorhersehbar ist und vieles, was wir als ausgeschlossen oder unwahrscheinlich erachten, doch noch funktionieren kann. Für die Studentin war das ein sehr schöner Moment der Bestätigung, für die Bewohnerin sicher eine Erfahrung von Selbstständigkeit, die sie nicht jeden Tag erlebt.

Ich möchte nicht verhehlen, dass trotz aller Bemühungen einige der von uns begleiteten Pflegebedürftigen dennoch in dieser Zeit für uns nicht erreichbar 
Abb. 6 Brief von Iuliia Rzhevkina, Teilnehmerin von UnVergessen, an einen russischsprachigen Bewohner

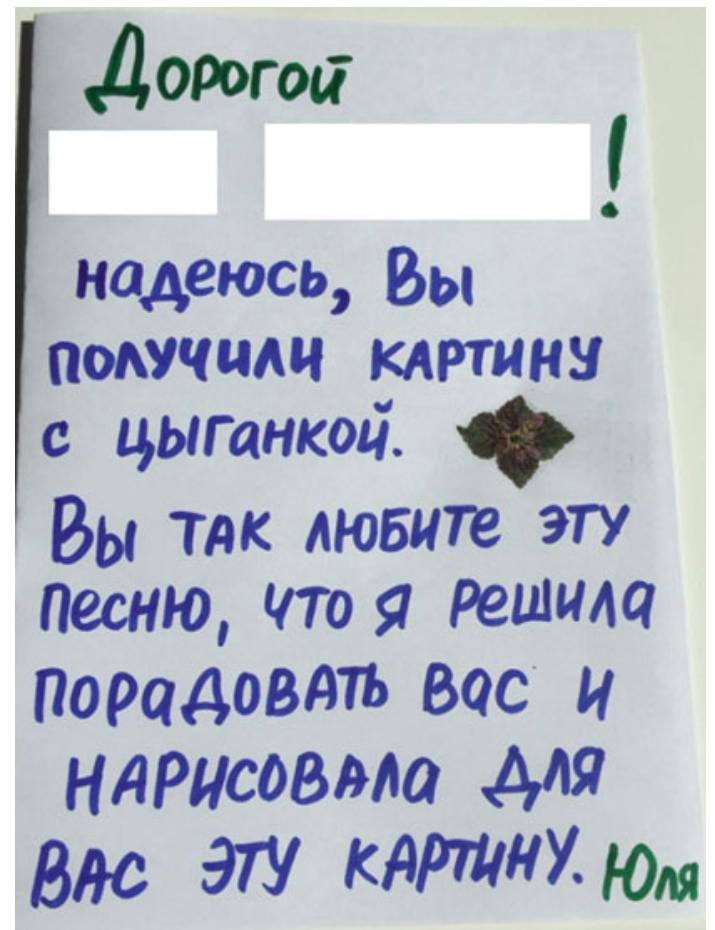

waren. Wie ich bereits erwähnt habe, kann es u.U. schwer sein, den Kontakt telefonisch zu halten, ebenso ist durch eine fortgeschrittene Demenzerkrankung der schriftliche Austausch erschwert bzw. unmöglich. Hier wäre eine Unterstützung von außen notwendig, die in einigen Fällen nicht vom entsprechend deutschsprachigem Personal übernommen werden konnte. So hatten wir zwei Personen in dem Projektdurchlauf, die wir leider für mehrere Wochen nicht begleiten konnten. In beiden Fällen handelte es sich um stark eingeschränkte Personen, eine von ihnen ist bettlägerig und erblindet. Obwohl alle Seiten sehr viel guten Willen bewiesen haben, konnten wir diese Personen leider nicht erreichen. Umso schöner war es dann, als die Pflegeheime wieder für Besucher geöffnet wurden. Dies war zwar nur unter strengen Auflagen möglich und sehr von der Lage in den einzelnen Einrichtungen abhängig, dennoch nutzen die Studentinnen dieser beiden Personen bereits ab Ende Mai/Anfang Juni diese Möglichkeit und fuhren wieder regelmäBig ins Pflegeheim. Hier möchte ich betonen, dass einige der Einrichtungen uns 
Abb. 7 Zeichnung von Iuliia Rzhevkina, Teilnehmerin von UnVergessen, zum Lied „Die Zigeunerin“

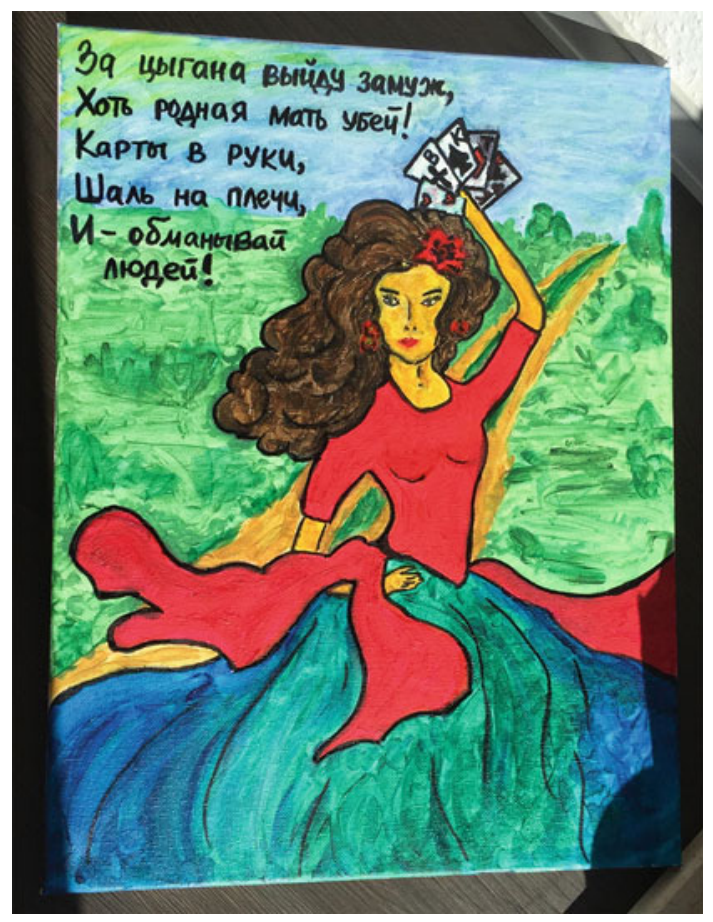

in dieser Zeit sehr entgegenkamen und ihrerseits großes Interesse daran hatten, dass unsere Besuche wieder aufgenommen wurden. Sie suchten nach möglichen Besuchszeitfenstern und - da leider in vielen Fällen die von uns besuchten Personen keine weiteren Besuche von z. B. Angehörigen bekommen - teilten uns die erlaubte Stunde zu. Dies ist keineswegs eine Selbstverständlichkeit, sondern ein Zeichen, wie wichtig auch aus Pflegeheimperspektive die Besuche sind. Und dies merkte man auch deutlich in den Schilderungen der Studentinnen, die diese wieder aufnahmen. Sie nahmen ihre Personen nicht mehr so aktiv wahr wie vor der Schließung, viele hörten vonseiten der Pflegekräfte von den negativen Auswirkungen der Isolation auch auf andere, nicht mehrsprachige Bewohner/innen. Insgesamt kam es ihnen oft so vor, als müssten sie von Neuem beginnen, die Person kennenzulernen und ein Vertrauensverhältnis zu ihnen aufbauen.

Hier möchte ich erwähnen, dass nicht alle studentischen Teilnehmerinnen die Besuche wieder aufnahmen. Da diese mit sehr strengen Auflagen und auch einer gewissen Herausforderung für die Studentinnen verbunden war, entschieden wir 
gemeinsam für jeden Einzelfall, welche Betreuung uns für die nächsten Wochen in der Konstellation am geeignetsten erschien. So war es z. B. klar, dass die Person, mit der der telefonische Kontakt nicht nur möglich, sondern sogar bereichernd war, auch weiterhin telefonisch begleitet werden würde. In einem zweiten Fall erschien die Videotelefonie zielführender - diese wurde dankenswerterweise vom Pflegepersonal ermöglicht. Hier handelte es sich auch um eine demenziell veränderte Person, von der wir wussten, dass sie auf die Masken sehr verwirrt reagiert. Um ihr also den Anblick einer maskierten Person zu ersparen, wählten wir lieber den zwar distanzierteren, aber unmaskierten Weg. Die anderen Teilnehmerinnen bemühten sich, so regelmäßig es ging wieder zu ihren pflegebedürftigen Personen zu fahren. Hier unterschieden sich die einzelnen Einrichtungen z. T. sehr stark. In einigen Fällen lief es sehr gut, die Absprachen waren klar, die Regeln ebenso. In anderen Fällen lief es schwieriger, manchmal fehlten entsprechende Informationen, wer die Besuchsperson ist und warum sie ,rein“ darf. Aber auch hier bemühten wir uns um Austausch, Aufklärung und vor allem um Verständnis für die so erschwerte Situation in den Einrichtungen. So wurde also für die meisten der Teilnehmerinnen ab Juni, bei manchen etwas zeitlich versetzt, wieder ein direkterer Austausch möglich. Allerdings stand dieser sehr unter dem Zeichen der Pandemie. Als besonders belastend wurden von den Studentinnen das Tragen der Maske und das Verbot der Berührung wahrgenommen. Gerade demenziell veränderte Personen sind stark auf die Mimik angewiesen und können sehr gut Emotionen im Gesicht lesen und verstehen (vgl. hierzu auch die Ausführungen von Y. Behrens im fünften Teil dieses Bandes). Mit einer Maske über dem halben Gesicht ist dies natürlich nicht möglich. Zudem kommt hinzu, dass diese Personen in keiner Weise verstehen können, wozu diese überhaupt nötig ist. In vielen Gesprächen war die Maske entsprechend auch ein zentraler Aufmerksamkeitspunkt: es wurde an ihr herumgezupft, sie abgesetzt, aufgefordert, sie wieder aufzusetzen und natürlich immer wieder thematisiert. So war klar, dass nicht an die Besuche vor der Schließung nahtlos übergangen werden konnte, sondern hier eine zweite Phase des Antastens nötig war. Die meisten Paare meisterten dies gut, und es kamen bald Berichte bei mir an, dass die Besuche wieder eine gewisse Form von routiniertem Ablauf finden. So wie vorher wurde es jedoch nicht mehr. Die Isolation hatte eindeutig Spuren hinterlassen und von unbeschwerten Besuchen kann wohl in keinem Fall die Rede sein. Seien es Ängste, doch jemanden im Heim anzustecken oder die sichtbaren Veränderungen der begleiteten Person - es galt vieles aufzuarbeiten.

In Bezug auf die Veränderungen der Pflegepersonen möchte ich betonen, dass diese in keiner Weise pauschal bei allen gleich zu beobachten waren. Auch hier waren sie höchst individuell und in manchen Fällen auch nur leicht bemerkbar. In 
allen Fällen wurde jedoch die Gesprächssituation, in der auf Distanz und Maske geachtet werden musste, als Einschränkung wahrgenommen, die sich stark auf den Austausch, die Atmosphäre und die Handlungsmöglichkeiten auswirkte und sehr oft Gesprächsgegenstand war. In anderen Fällen waren deutlich gravierendere Entwicklungen eingetreten. Ich möchte hier nicht darüber mutmaßen, worauf diese zurückzuführen sind und ob sie nicht eventuell auch unter normalen Bedingungen eingetreten wären, da in der Zwischenzeit ja immerhin einige Wochen ins Land gezogen sind, in denen sich Erkrankungen auswirken und auch ohne Isolation zu Veränderungen führen können. Zudem möchte ich auch hier noch einmal betonen, dass alle kooperierenden Pflegeheime überaus aktiv sind und ihnen das Wohl ihrer Bewohner/innen sehr am Herzen liegt. Wäre dies nicht der Fall, wären sie wohl kaum zu Kooperationspartnern geworden. Dies zeigt auch der Austausch mit ihnen, in dem sie auch ihrerseits betonen, was sie alles versucht haben, um die Folgen der Isolation für die Bewohner/innen so gering wie möglich zu halten (darauf führe ich auch das große Interesse vonseiten der Pflegeheime an der Aktion Briefe gegen die Einsamkeit zurück, auf die ich im folgenden Abschnitt eingehe). Leider sind jedoch auch hier Grenzen gesetzt, die sich - wieder einmal - in den Fällen anderssprachiger Pflegebewohner/innen schneller und deutlicher zeigen. Ich möchte als Beispiel Herrn Mironow ${ }^{5}$ vorstellen, den Sie in den Ausführungen von N. Friesen (vgl. Friesen im fünften Teil dieses Bandes) genauer kennenlernen werden. Herr Mironow ist ein russischsprachiger Mann, der seit drei Jahren von UnVergessen begleitet wird. Er leidet an einer demenziellen Erkrankung und ist infolge dessen bereits recht stark kognitiv eingeschränkt. In der Beobachtung seiner Reaktionen wird klar, dass Herr Mironow Deutsch verstehen kann, er spricht es aber kaum. Zwar verwendet er einzelne Wörter und Floskeln auf Deutsch, seine Hauptkommunikationssprache ist dabei aber Russisch. Auf ihr kann er sich durchaus gut verständigen, spricht in vollständigen Sätzen und Zusammenhängen und nimmt an einem Gespräch teil. Dies zeigen die Berichte und Aufnahmen der Studentinnen und auch russischsprachiger Pflegekräfte, die es in diesem Heim gibt und die mit ihm auch auf Russisch kommunizieren. Über die Dauer der drei begleiteten Jahre hat sich Herr Mironow verändert - das Fortschreiten seiner demenziellen Erkrankung ist spürbar. Besonders geschwätzig war er nie, auf Fragen zu seiner Familie und seinem Beruf ging er auch am Anfang der Besuche nicht ein, dennoch fanden Gespräche statt, an denen er aktiv teilnahm. Schnell zeigte sich seine Vorliebe für das Kartenspiel. So füllten sich die Besuche damit, wobei je nach Tagesform das Spiel mehr oder weniger an den

${ }^{5}$ Der Name wurde geändert. 
Regeln orientiert ablief. Herr Mironow war zwischenzeitig immer mal wieder auch für längere Zeit - im Krankenhaus. Und jedes Mal, wenn er zurückkam, konnte man eine Verschlechterung seines kognitiven Zustandes bemerken. Er war verwirrter, konnte sich schlechter konzentrieren und musste stärker motiviert werden, in Interaktion zu treten. Er schien also recht sensibel auf Veränderungen seines Umfeldes zu reagieren. Nach solchen Krankenhausaufenthalten dauerte es immer eine Weile, bis wieder ein routinierter Ablauf in die Besuche kam und er sich z. B. auf das Kartenspiel einließ. Die Veränderungen - wohl durch die demenzielle Erkrankung hervorgerufen - kamen schleichend und wellenförmig, häufig ausgelöst durch einen solchen Krankenhausaufenthalt. Als nach zwei Jahren Begleitung die studentische Person wechselte, fiel es der Nachfolgestudentin, Kristina Harin, schwer, an das häufige Kartenspiel anzuknüpfen. Mittlerweile gab es keine guten Tage mehr, an denen die Regeln noch präsent waren, an schlechten Tagen war es ihm anscheinend unklar, was er mit den Karten überhaupt sollte. So veränderte sich der Modus der Besuche. Nun hatte Herr Mironow mehr Interesse daran, in Begleitung seiner Studentin im Aufenthaltsraum oder anderen Plätzen, an denen Leben war, zu sitzen, dieses zu beobachten und ab und an zu kommentieren. Die Beobachtung des Fahrstuhls gehörte mit dazu. Kristina Harin ließ sich darauf ein und beide Seiten schienen mit den Besuchen zufrieden und einen Umgang miteinander gefunden zu haben. Das Kartenspiel hatte dabei weiterhin seinen Platz, es kamen aber andere Aktivitäten hinzu. In ihrem Abschlussbericht schreibt die Studentin rückblickend:

\begin{abstract}
„Bei meinem ersten Besuch war ich aufgeregt und nervös, weil ich nicht wusste, wie Herr Mironow auf mich reagieren wird. Zu meiner Überraschung verlief der erste Besuch besser, als ich gedacht habe. Herr Mironow hat viel gelacht und sogar Witze erzählt. Darüber war ich sehr froh und bin mit einem guten Gefühl nach Hause gegangen.

Bis Ende Februar verliefen die Besuche sehr gut, Herr Mironow hat zwischendurch einiges erzählt, wir haben gemeinsam Karten gespielt, und obwohl wir manchmal uns nichts zu sagen hatten war die Atmosphäre angenehm und es war einfach nur ein gutes Gefühl mit ihm da zu sitzen und einen Kaffee zu trinken.“ (Harin, 2020, S. 5).
\end{abstract}

Dann kam jedoch die Schließung der Heime. Herr Mironow bekam von der Studentin regelmäßig Briefe geschickt. Da wir wussten, dass es russischsprachiges Personal im Heim gab, hofften wir, dass sie ihm gegeben und ggf. vorgelesen wurden. Allerdings erreichten ihn die Briefe zunächst nicht, da Herr Mironow schon kurz darauf erneut im Krankenhaus war. Wir wissen allerdings, dass er die Briefe bekommen hat, da sie in seinem Zimmer aufgehängt waren, als die Studentin ihn wieder besuchen durfte. Als er aus dem Krankenhaus zurückkehrte, hatte 
sich eine Verschlechterung seines Zustandes eingestellt, und so fand ihn Kristina Harin in einem deutlich schlechteren Zustand wieder, als die Besuche bei ihm als eine der ersten bereits Ende Mai wieder möglich und ausgezeichnet koordiniert abliefen. Es war fast kein Austausch mehr möglich, er erschien deutlich irritiert über die Maske, und der Studentin fiel es schwer, einen Zugang zu ihm zu finden. In ihrem Bericht schreibt sie:

\begin{abstract}
„Herr Mironow war verwirrt, als ich nach langer Zeit wieder zu ihm kam und mit der ganzen Situation überfordert. Er hat nicht verstanden, wieso wir die Masken tragen müssen und wer ich jetzt eigentlich bin. Ich war besorgt um Herrn Mironow, da ich gemerkt habe, dass es ihm nicht mehr gut geht. Bei dem weiteren Treffen ist er im Sitzen eingeschlafen.
\end{abstract}

Die meiste Zeit ist es vorgekommen, dass ich ins Pflegeheim gefahren bin und er geschlafen hat. Es gab auch Treffen, da war Herr Mironow gut drauf, er hat zwar nicht viel geredet, aber er hat mir zugehört.

Allgemein habe ich gemerkt, dass er noch stiller geworden ist als vorher. Er klagte über Schmerzen und war desinteressiert bei meinen Besuchen und was ich ihm zu erzählen habe." (Harin, 2020, S. 10 f.)

Bei ihrem letzten Besuch erschien Herr Mironow stark abgemagert. Aus dem Pflegeheim erfuhr ich, dass er das Essen verweigert und auch von ihrer Seite zeigte man sich sehr besorgt über seinen Gesundheitszustand. In gegenseitiger Absprache - mit der Studentin und dem Pflegeheim - stellten wir die Besuche bei ihm ein, da sie uns allen als zusätzliche Belastung für Herrn Mironow und auch für die Studentin erschienen.

Ich möchte noch einmal betonen, dass Herrn Mironows Zustand sich über die Jahre hinweg schleichend verschlechtert hat und sich das Pflegeheim als überaus engagiert gezeigt hat, alles zu tun, um seine Situation so angenehm wie möglich zu gestalten. Es kann durchaus sein, dass diese rapide Verschlechterung auch unter normalen Umständen eingetreten wäre, dennoch bleibt der Eindruck, dass die Einschränkungen und die Auswirkungen der Corona-Pandemie hier ein Übriges getan und diese Entwicklung beschleunigt haben. Herr Mironow ist hier ein Einzelbeispiel, leider haben wir jedoch von weiteren Fällen aus den Pflegeeinrichtungen gehört und konnten ähnliche Entwicklungen auch bei anderen unserer begleiteten Personen erkennen. Es ist unzweifelhaft, dass die Pandemie ihre Auswirkungen auf jeden von uns hat - auf diese vulnerable Gruppe jedoch logischerweise umso stärker und mit fataleren Folgen. Ihnen fehlen schlicht die Möglichkeiten und die Zeit, sich von diesen Einschränkungen zu erholen. Was verloren ist, kehrt in ihrem Fall nicht mehr wieder. Umso wichtiger erscheint es, einen speziellen 
Fokus auf diese Gruppe von Menschen zu legen und so schnell wie möglich zu einem normalen Austausch mit ihnen zurückzukommen. Es bestehen berechtigte Hoffnungen, dass dies im Laufe des Jahres 2021 eintreten und die momentane Projektrunde ihre Besuche in gewohnter Weise bald wieder aufnehmen kann. Eine Rückkehr zur Zeit davor wird auch dies sicher nicht sein. Aber das liegt in der Natur von Veränderungen und kann auch die Chance auf positive Entwicklung bergen.

Vonseiten des Projektes sind in den letzten Monaten viele neue und durchaus gewinnbringende Erfahrungen hinzugekommen, die den weiteren Weg prägen werden. Um nur einige zu nennen, sind dies eine bewusstere Wertschätzung des direkten Miteinanders, der geschärfte Blick auf Auswirkungen, die Veränderungen im Lebensalltag haben können ${ }^{6}$, und in vielerlei Hinsicht eine Sensibilisierung und gewachsenes Verständnis für die Belange und z. T. belastenden Situationen in Pflegeeinrichtungen. Diese Erfahrungen werden uns sicher auf dem weiteren Weg begleiten.

Abschließend möchte ich noch auf eine letzte Erfahrung aus dieser außergewöhnlichen Zeit eingehen: Das Netzwerk zwischen Universität, Pflegeheimen und auch ehemaligen Studierenden ist stabil, funktioniert und konnte sogar ausgebaut werden. Als Zeichen dessen möchte ich ein konkretes Beispiel bringen: Ein kooperierendes Pflegeheim trat an die Projektleitung heran und bat um Hilfe. Den Bewohner/innen war es durch die Kontaktsperre nicht mehr möglich, das Heim zu verlassen und sich private Dinge zu kaufen. Da zugleich die Pflegekräfte durch die besondere Situation vollständig eingebunden waren, konnten diese nicht einspringen. Und so fragte die Leitung an, ob UnVergessen tätig werden könne. Eine entsprechende Bitte habe ich in die Projektrunde und das Alumni-Netzwerk gegeben und innerhalb von zwei Tagen haben sich drei Student/innen (eine aktuelle und zwei ehemalige Teilnehmer/innen) gefunden, die auf ehrenamtlicher Basis über die Dauer des ersten Lockdowns zweimal die Woche zu dem Pflegeheim gefahren sind und dort die Einkaufswünsche der Bewohner/innen erfüllten. Dies war für mich eine Bestätigung, dass das Ziel, eine Brücke zwischen Pflegeheim

\footnotetext{
${ }^{6}$ An dieser Stelle möchte ich ein kleines Beispiel bringen: Normalerweise beinhaltet das Vorbereitungsseminar von UnVergessen eine recht ausführliche Diskussion darüber, welche Veränderungen für Menschen mit dem Renteneintritt durch den Wechsel des Alltags und der veränderten sozialen Kontakte verbunden sind. In dem diesjährigen Seminar konnte das Verständnis dafür unmittelbar hergestellt werden, da sich der Vergleich mit der eigenen Situation zu Zeiten des ersten Lockdowns nahezu aufdrängte und jeder am eigenen Leib erfahren hat, welche psychischen und auch physischen Folgen auch für sie als junge Menschen damit verbunden sein können. Ob diese Erfahrung auch dauerhaft und gesellschaftlich zu einer stärkeren Sensibilisierung vulnerabler Gruppen führt, bleibt abzuwarten und zu erhoffen.
} 
und Universität bzw. in diesem Fall zwischen Hilfesuchenden und Hilfegebenden zu schlagen erreicht ist.

\section{Briefe gegen die Einsamkeit}

Aus den oben geschilderten positiven Erfahrungen des neuartigen Kontaktes zwischen Studierenden und Pflegebewohner/innen ist sehr schnell im Frühjahr 2020 die Idee entstanden, diese Form des Austausches auf mehr Beteiligte auszudehnen. Schließlich waren durch die Corona-bedingten Einschränkungen nicht nur die mehrsprachigen Bewohner/innen von Pflegeheimen von Abgrenzung und Isolation betroffen, keiner durfte mehr Besuche bekommen. Dies traf einige sehr hart und unvermittelt, ganz gleich, welche Sprache sie sprechen. Nach Rücksprache mit unseren Kooperationspartner/innen und deren Interessensbekundung habe ich mich dazu entschieden, die Projektarbeit auszudehnen und um eine großangelegte neue Aktion zu erweitern (Abb. 8).

In der Folge ist Ende März 2020 die Aktion „Briefe gegen die Einsamkeit“ ins Leben gerufen worden, die einen deutlich größeren Kreis an Menschen anspricht. Über unterschiedliche Kanäle - vorrangig über soziale Netzwerke der RuhrUniversität Bochum - wurden über das Projekt UnVergessen junge Menschen unter dem Motto „Gemeinsam werden auch neue Wege begehbar!“ aufgerufen, ein Zeichen der Solidarität zu setzen und den Pflegeheimen - und im Besonderen den dort lebenden Personen - zu zeigen, dass sie nicht vergessen sind (vgl. für diese Ausführungen hier Karl, 2020).

Abb. 8 Logo „Briefe gegen die Einsamkeit“, Graphik P. Wolk

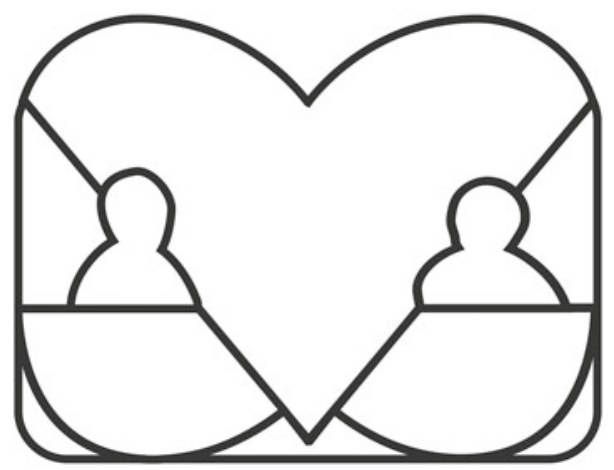


Dies geschah in der Form, dass interessierte junge Menschen Briefe, selbstgebastelte Grüße und andere Aufmerksamkeiten an Menschen in Pflegeeinrichtungen schicken. Gerade über den Brief kann bei den Vertretern einer meist älteren Generation im besten Fall eine Erinnerung an alte Zeiten wachgerufen werden. Zudem ist gewiss, dass sich jeder über einen persönlichen Brief freut - zeigt er doch, dass jemand an einen denkt und sich Zeit nimmt, diesen Gruß zu formulieren.

Im Rahmen der Teilnahme wird jeweils eine interessierte junge Person an eine Person, die in einem unserer kooperierenden Pflegeheime lebt, vermittelt. Die junge Person schreibt einen ersten Brief zur Kontaktaufnahme und schickt diesen in das jeweilige Pflegeheim. Die dort lebende adressierte Person entscheidet selbst, ob und in welcher Form sie wiederum antwortet. Um diese Rückantwort zu erleichtern, wird jedem ersten Brief ein rückadressierter und frankierter Umschlag beigelegt. Die Hoffnung dabei ist, dass sich auf diese Weise eine Brieffreundschaft zwischen zwei Personen entwickelt, die zunächst über die Zeit der sozialen Isolierung hilft - und vielleicht sogar diese Zeit überdauert, sei es in fortgeführter schriftlicher Form oder in persönlichen Kontakten.

Nach unserem Aufruf zur Beteiligung an der Aktion Ende März/Anfang April 2020 haben sich innerhalb kürzester Zeit sehr viele engagierte Personen gefunden, die sich am Briefeschreiben beteiligen möchten. Ebenso haben sich viele Einrichtungen gefunden, die ihrerseits Interesse haben, dass ihre Bewohner/innen postalische Grüße erhalten. Innerhalb eines Monats konnten so 187 junge Menschen an insgesamt 207 Bewohner/innen von 17 unterschiedlichen Pflegeheimen im Ruhr-Gebiet vermittelt werden. Zum Teil schreiben einige junge Menschen mehr als einer Person, in den meisten Fällen ist jedoch eine 1:1-Vermittlung umgesetzt. Der Höhepunkt der Aktion mit den meisten Anfragen und entsprechenden Vermittlungen war bis zum Monat Mai. Danach kamen in den folgenden Monaten (ca. bis Mitte Juli) noch einige weitere Kontakte zustande und auch einige Monate später, speziell um die Weihnachtszeit 2020, kommen immer mal wieder vereinzelte Anfragen von Personen, die von der Aktion gehört haben und sich gerne engagieren möchten. So ist die Zahl kontinuierlich gewachsen, die meisten Vermittlungen erfolgten jedoch innerhalb der ersten Wochen, sodass diese Zahlen hier näher ausgeführt werden sollen:

Anfang Mai 2020 hatten sich knapp 400 Menschen gefunden, die sich initiiert durch diese Aktion gegenseitig Briefe schreiben. Die meisten von ihnen schreiben auf Deutsch, aber es sind auch andere Sprachen vertreten: Russisch, Polnisch, Italienisch, Spanisch und Chinesisch. 
Die Aktion war dabei so angelegt, dass vonseiten der jungen Menschen drei Interessensgruppen in unterschiedlicher Weise teilnehmen und sich sozial und auch wissenschaftlich einbringen konnten:

Die erste Gruppe bestand aus Personen, die Interesse an der Übernahme einer Brieffreundschaft haben, aber daneben keine weiteren Verpflichtungen eingehen wollten. Für diese Menschen übernahm UnVergessen die Vermittlung an eine Person in einem Pflegeheim, der sie dann selbstständig schreibt. Im Sinne einer Absicherung und des Nachweises der Nachhaltigkeit der Aktion werden diese Menschen gebeten, mit der Projektleitung in Mailkontakt zu bleiben und sie über eine Rückantwort aus dem Pflegeheim und den weiteren Verlauf der Partnerschaft zu informieren. Im Mai 2020 umfasste diese Gruppe 35 Personen, die 35 Pflegebedürftigen Briefe und Grüße sandten. Aus entsprechenden Rückmeldungen weiß ich, dass einige von ihnen Antworten bekommen haben und mit ihrer/m Brieffreund/in in Austausch stehen. Dies betrifft in etwa ein Drittel der vermittelten Paare. Ein weiteres Drittel meldete mir im Laufe der Wochen bzw. Monate zurück, dass sie zwar ihrerseits Briefe verschickt, aber leider keine Rückantwort erhalten haben. Z. T. verschickten die Personen trotzdem weiterhin Grüße oder baten um die Vermittlung einer zweiten Briefperson. Dieser Bitte kam ich, solange mir durch die Pflegeheime interessierte Menschen genannt wurden, gerne nach und konnte so einen Teil der interessierten Menschen erneut vermitteln. Über das letzte, nicht ganze Drittel kann ich in diesem Fall keine Aussage machen, da ich von ihnen nach der Vermittlung keine weitere Rückmeldung bekommen habe.

Die zweite Gruppe ist die zahlenmäßig stärkste. Sie umfasste im Mai 2020112 Personen, die sich ebenfalls für die Teilnahme angemeldet haben, aber - im Unterschied zur ersten Gruppe - an einem Austausch mit anderen Teilnehmer/innen interessiert sind. Dafür wurde die Möglichkeit geschaffen, sich über die Lernplattform Moodle in die Projektgruppe einzutragen und dort aktiv in Austausch zu treten. Dieser umfasst bspw. das Teilen von eigenen verschickten Grüßen oder auch der Antworten, Diskussionen zu bestimmten Themen sowie Einträge in Chatforen. Über diese besteht die Möglichkeit, sich z. B. über die Erfahrungen auszutauschen, die sie durch das Briefeschreiben machen oder sich gegenseitig Rat und Trost zu geben, wenn die Antwort von der/dem Briefpartner/in (noch) aussteht.

Diese ersten zwei Gruppen setzen sich aus Menschen zusammen, die in irgendeiner Weise mit der Ruhr-Universität Bochum verbunden sind, und solchen, die über andere Kanäle von der Aktion erfahren haben und daran teilnehmen wollten. Eine Verbindung zur Universität - geschweige denn der Status als Studierender - ist hier keine Voraussetzung. So nehmen auch Mitarbeiter/innen der Universität teil, Studierende anderer Universitäten oder Hochschulen, Freunde und Verwandte 
von Studierenden und andere assoziierte Personen, die keinen direkten Bezug zu Bochum oder zur Universität haben.

Bei der dritten Gruppe sieht dies anders aus. Diese besteht vollständig aus Studierenden der Ruhr-Universität Bochum. Es handelt sich um insgesamt 40 Studierende sehr unterschiedlicher Fächer und Fakultäten, die ihre Teilnahme mit dem Besuch einer Lehrveranstaltung kombinieren. Diese fand im Sommersemester 2020 begleitend zur Briefaktion statt und kann bei Interesse im Wintersemester 2020/2021 durch eine Folgeveranstaltung ergänzt und zu einem Modul erweitert werden. Die Lehrveranstaltung ebenso wie das Modul können in unterschiedlicher Weise in das Curriculum der jeweiligen Fächer integriert werden. Dabei wird der variierende Bedarf an Leistungspunkten mit jeweils angepassten Leistungsnachweisen bedient. Die Studierenden reflektieren im Laufe der Lehrveranstaltung verschiedene Aspekte der Aktion und ihrer eigenen Teilnahme, analysieren exemplarisch Briefe von Studierenden und Antworten aus den Pflegeheimen und arbeiten diese nach jeweils individuellen Gesichtspunkten auf. Dabei greift wiederum der Ansatz des Forschenden Lernens: Die Studierenden entwickeln eigenständig und auf Grundlage ihrer Interessen, Fachrichtungen und damit verbunden ihrer Expertise eine Fragestellung, unter der sie ausgewählte Facetten der Briefaktion beleuchten. In begleiteten Schreibarbeiten fassen sie diese Reflexion, Aufarbeitung und Analyse zusammen und reichen sie in Form eines Abschlussberichtes ein. Damit ist für diesen Kreis an Teilnehmer/innen neben dem sozialen Engagement eine neuartige Möglichkeit gegeben, die aktuelle Situation auch für sich selbst aufzubereiten und aus ihr ein für sie bislang neues Forschungsfeld zu entwickeln.

Wie bereits in den Ausführungen zur dritten Teilnehmer/innengruppe ersichtlich wurde, ist die Aktion Briefe gegen die Einsamkeit von Beginn an so angelegt, dass die Teilnahme am Projekt nicht nur mit sozialem Engagement einhergeht, sondern auch die wissenschaftliche Seite und eine entsprechende Aufbereitung zum Zuge kommen. Die Briefe, die im Rahmen dieser Aktion entstehen, sind in vielerlei Hinsicht für die Wissenschaft von großer Bedeutung. Zunächst einmal können sie als besondere Form von Zeugnissen einer Zeit stehen, die bislang noch kaum einer so erlebt und auch nicht erwartet hat. Hier sind sie für die Dokumentation und Aufbereitung von Interesse, da in vielen der Briefe die gesundheitliche Lage und die sozialen und psychischen Folgen thematisiert werden. Zum zweiten wird durch den Briefwechsel der Austausch zwischen Generationen festgehalten: In allen Fällen handelt es sich bei den Briefeschreibern außerhalb des Pflegeheimes um junge Menschen, vorrangig um Studierende oder junge Erwerbstätige, selbst die Ältesten unter ihnen stehen noch aktiv im Berufsleben. Die meisten Briefeempfänger/innen in den Pflegeheimen hingegen sind Vertreter einer älteren 
Generation (einige wenige Ausnahmen - insgesamt drei - von jüngeren Bewohner/innen gibt es dabei). Die älteste Teilnehmerin ist im Jahr 1915 geboren und wird demnächst 105 Jahre alt. So wird deutlich, dass hier zwei sehr unterschiedliche Generationen mit entsprechend unterschiedlichen Lebenserfahrungen und Erinnerungen zueinanderkommen. In welcher Weise diese Themen in den Briefen auftreten und als Faden durch die Kommunikation leiten, ist von großem Interesse. Und der dritte Aspekt umfasst die schriftlichen Produkte, die von den älteren Menschen geschrieben werden. Diese sind aus gerontolinguistischer Sicht von Wert, da es kaum vergleichbare Sammlungen an Schriftstücken dieses Personenkreises in solch einem Umfang gibt. Hier lassen sich unterschiedlichste Fragestellungen formulieren, die mithilfe der so gesammelten Daten bearbeitet werden können (mehr dazu s.u.).

Diese Verquickung von sozialem Engagement, intergenerationellem Austausch und wissenschaftlichen Aspekten ist hier, ebenso wie im Projekt UnVergessen, intrinsisch angelegt. Aus meiner Sicht ist gerade dies der Grund für die Einzigartigkeit und auch den Erfolg dieser beiden Projekte: Die einzelnen Komponenten greifen nahtlos ineinander und können sich gegenseitig gewinnbringend befruchten. So ist z. B. gerade die wissenschaftliche Aufbereitung ein überaus wichtiger Punkt, da durch die Wissenschaft die Situation der Menschen in Pflegeheimen analysiert werden kann, auf dieser Grundlage Probleme, Desiderata aber auch positive Aspekte herausgearbeitet werden können, die im nächsten Schritt zur Verfügung stehen, um neue Konzepte passgenau für den Personenkreis ausarbeiten zu können. Zudem tragen wissenschaftliche Ergebnisse bzw. eine entsprechende Berichterstattung über die Tätigkeiten zu einer besseren Sichtbarkeit bei, die hoffentlich zu einer größeren Sensibilisierung für die hier relevanten Themen führt. Insofern dient hier auch die Wissenschaft einem sozialen Zweck - der Kreis schließt sich bzw. beginnt von neuem.

In diesem Kontext ist es relevant, auf die rechtlichen Rahmenbedingungen der Teilnahme an der Aktion Briefe gegen die Einsamkeit hinzuweisen. Alle Teilnehmer/innen verpflichten sich mit der Teilnahme an der Aktion, die gewonnenen Daten und persönlichen Informationen aus den Pflegeheimen und über die Pflegebedürftigen nicht mit Dritten zu teilen. Zugleich besteht die Möglichkeit, die Briefe und Dokumente in anonymisierter Form der Wissenschaft zur Verfügung zu stellen. Eine entsprechende Freigabe der Briefe wird dabei durch schriftliche Einverständniserklärungen abgesichert. Von den 187 Teilnehmer/innen aufseiten der jungen Menschen haben lediglich 29 Personen einer wissenschaftlichen Verwendung nicht zugestimmt, alle anderen sind bereit, ihre Briefe zu wissenschaftlichen Zwecken an die Projektleitung zu übergeben. Auf diese Weise konnte bereits in den ersten Wochen der Briefaktion eine Vielzahl an Briefen zur Kontaktaufnahme 
(insgesamt über 100) gesammelt werden. Einige Eindrücke von diesen, wie auch gemalte und gebastelte Ostergrüße finden sich auf der Projekthomepage unter https://www.un-vergessen.de/aktion-briefe-gegen-die-einsamkeit.

Parallel zu den Briefen zur Kontaktaufnahme kamen tatsächlich sehr bald erste Reaktionen von den Pflegebedürftigen zurück. Ich erinnere mich sehr gut an den Moment, als ich von einer Studentin die Nachricht der ersten Rückantwort bekam - ich freute mich sehr, da mir dies zeigte, dass sich der Aufwand gelohnt hat und tatsächlich auf diese Weise Menschen zueinanderkommen und sich austauschen können.

Und zum Glück blieb es nicht bei dieser einen Rückantwort. Schon kurze Zeit später (Mitte Mai) waren es 32 Briefe aus Pflegeheimen, über die ich Nachricht bekam. Einige Paare standen zu dem Zeitpunkt sogar schon im regen Austausch und hatten sich gegenseitig jeweils zwei bis drei Briefe geschickt. Insgesamt differieren die Antworten, die Frequenz und Schnelligkeit der Rückantworten sehr stark. So gibt es Bewohner/innen, die ganze Seiten innerhalb weniger Tage zurückschicken und sehr viel von sich erzählen, andere schreiben nur kurze Grüße zurück, formulieren diese aber selbst, wiederum andere diktieren ihre Antwort einer Pflegekraft bzw. einer Person des Sozialen Dienstes oder kreuzen vorformulierte Fragen an. Hier sind die Reaktionen so divers, wie die Personen dahinter, und stark in Abhängigkeit der jeweiligen Möglichkeiten gestaltet. Z. B. thematisieren viele ihre Handschrift (entschuldigen sich für diese und erläutern, warum sie bspw. so zitterig ist) oder verdeutlichen, dass ihnen das Schreiben schwerfällt. Aber es kommen Reaktionen zurück, die vor diesem Hintergrund eine noch viel größere Bedeutung erhalten. Dabei spricht aus jedem einzelnen Rückbrief die Freude, die durch den Empfang der Briefe empfunden wurde und das Interesse, mit der anderen Person weiterhin in Kontakt zu bleiben. In vielen Fällen wird sogar vermittelt, dass sie Interesse an Telefonaten und direkten Besuchen (nach Corona) haben. Dies sind schöne Zeichen dafür, dass über den Brief tatsächlich neue Kontakte hergestellt werden können und sich so in ganz klassischer Art (Brief-)Freunde finden.

Um einen kleinen Eindruck von den unterschiedlichen Briefen zu vermitteln, möchte ich hier einige Impressionen aus den Briefen der Pflegebewohner/innen abdrucken.

Im ersten Fall handelt es sich um den ersten Antwortbrief einer Person. Diesen verfasste sie innerhalb weniger Tage nach der Kontaktaufnahme durch eine Studentin - Jasmin Batler. Diesem ersten, kürzeren Brief folgte wenige Tage später ein ausführlicherer Brief. Zum momentanen Zeitpunkt (Januar 2021) stehe ich mit der Studentin dieses Briefpaares, Jasmin Batler, immer noch im Kontakt und weiß von ihr, dass sie sich mit ihrer Brieffreundin sehr regelmäßig austauscht. Dabei 
entstehen z. T. seitenlange Briefe, in denen sie sich auch über aktuelle Themen, wie bspw. im Herbst 2020 über die Wahl des US-Präsidenten, austauschen. Sie schicken sich Fotos, berichten von ihren Lieblingsbüchern und ehemaligen oder geplanten Reisezielen. Jasmin Batler hat über diesen Briefaustausch eine sehr interessante Arbeit geschrieben, in der sie schildert, wie überrascht sie war, als sie feststellen musste, wie viel sie mit ihrer Brieffreundin gemeinsam hat und wie gut sie sich mit ihr austauschen kann. Dieses Gefühl war für sie der Ausgangspunkt, darüber nachzudenken, wie es kommt, dass sie mit einer anderen Vorstellung an den Austausch herangetreten ist. Sie ging in einer kleinen und damit natürlich nicht repräsentativen Umfrage unter Gleichaltrigen dieser Frage bei Anderen nach und musste auch bei ihnen feststellen, dass überwiegend die Meinung geäußert wurde, man würde im Austausch mit älteren fremden Personen wenig Gemeinsamkeiten erwarten (im Gegensatz dazu traf dies auf bekannte ältere Personen nicht zu) (vgl. Batler, 2020). Umso schöner und wertvoller erscheint vor diesem Hintergrund die gegenteilige Erfahrung der Studentin. Wie sie es selbst äußert, ist ihre Brieffreundin mittlerweile zu einer echten Freundin geworden, bei der der Altersunterschied und auch die Unterschiede in den Lebensumständen zwar natürlich noch bestehen, aber nicht mehr leitend und beeinflussend im Vordergrund des Austausches stehen.

Bei ihrer Brieffreundin handelt es sich um eine ca. 80jährige Frau ${ }^{7}$, die an Parkinson erkrankt ist und daher Schwierigkeiten mit ihrer Handschrift hat. Dies hindert sie aber nicht daran, selbst zu schreiben (Abb. 9 und 10):

Über die Brieffreundschaft von Jasmin Batler ist ein Artikel der RUB-News erschienen, der diese Ausführungen hier schön ergänzt: https://news.rub.de/stu dium/2020-07-02-projekt-briefe-gegen-die-einsamkeit.

Als Beispiel für eine Rückantwort, die von einer anderen Person verschriftlicht wurde, steht hier der folgende Rückbrief (Abb. 11):

Solcherlei Rückantworten, die von Pflegekräften, Mitarbeiter/innen des Sozialen Dienstes oder auch Angehörigen geschrieben wurden, sind im Lauf der Monate vermehrt eingetroffen. Meist benötigen diese Antworten mehr Zeit, in der mir die jungen Briefeschreiber/innen häufig schon rückgemeldet hatten, dass sie keine Reaktion bekamen. Umso größer war dann die Freude, wenn noch unverhofft ein Brief an sie kam. In allen dieser Fälle wurde, wie auch in dem abgebildeten Brief, thematisiert, dass nicht die angeschriebene Person selbst schreibt,

\footnotetext{
${ }^{7}$ Zur Erläuterung: In ihrem Brief schreibt sie, dass sie „38“ Jahre alt sei. Aus dem Heim habe ich jedoch die Information, dass sie über 80 ist, was auch aus dem beigelegten Foto der Person sehr deutlich hervorgeht. Hier scheint es sich entweder um eine klassische Verschreibung zu handeln (gemeint wäre dann 83) oder um eine Art Scherz (dafür sprechen die Anführungszeichen). Dies wird in den Briefen nicht aufgelöst.
} 


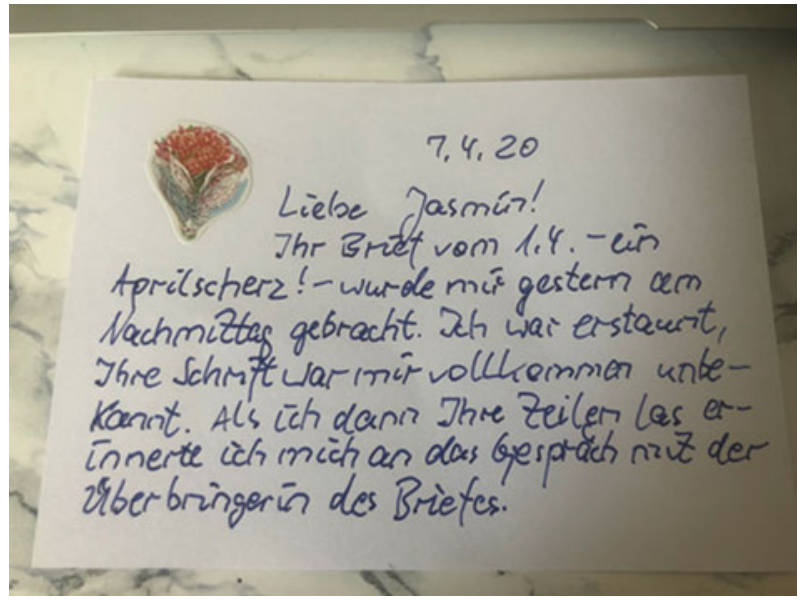

Abb. 9 Brief aus dem Pflegeheim: Eine an Parkinson erkrankte Frau schreibt ihrer Brieffreundin zurück (Teil 1)

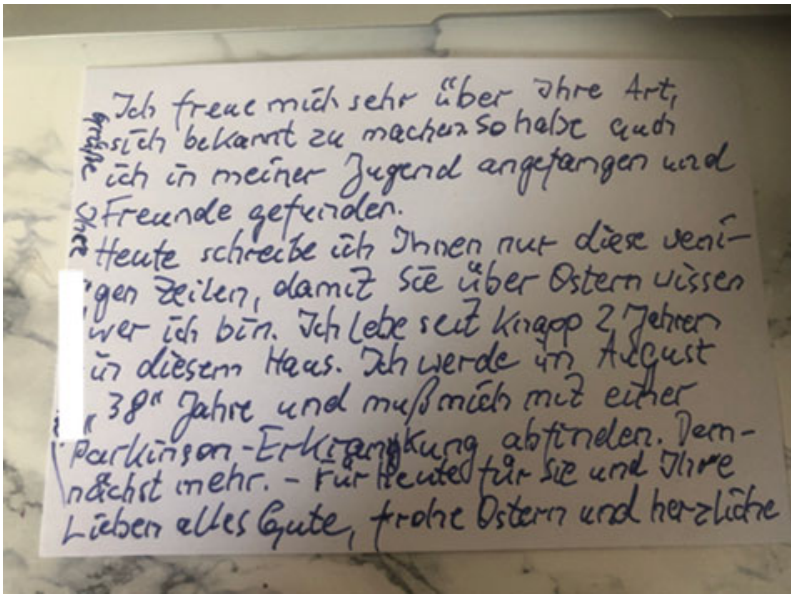

Abb. 10 Brief aus dem Pflegeheim: Eine an Parkinson erkrankte Frau schreibt ihrer Brieffreundin zurück (Teil 2) 


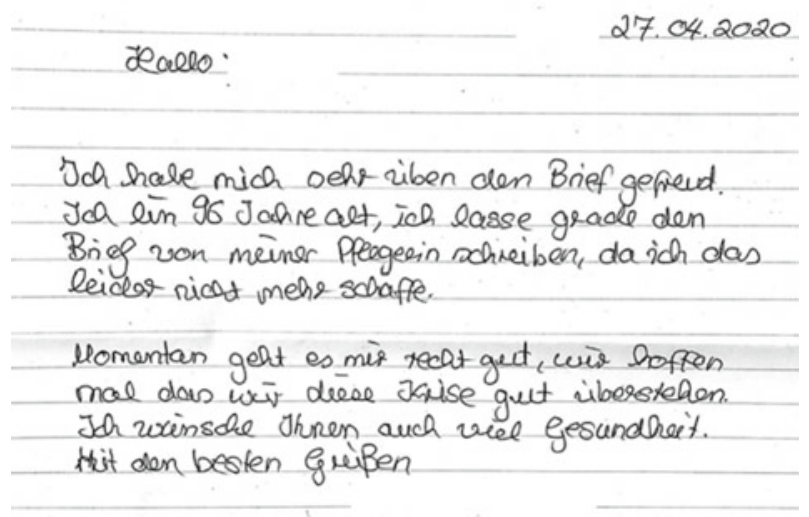

Abb. 11 Brief aus dem Pflegeheim, verfasst von einer Pflegerin

sondern in ihrem Auftrag oder von ihr diktiert eine andere Person den Stift führt. Die Freude über eine solche Information bei den jungen Teilnehmer/innen war jeweils groß und die meisten schrieben daraufhin weiterhin Briefe und schickten kürzere Grüße mit Gebasteltem und vorgefertigten Antwortmöglichkeiten. Von einigen dieser Briefpaare habe ich die Rückmeldung bekommen, dass sie auch jetzt, Monate später, noch im Austausch stehen. Zwar müssen sich die jungen Menschen bis zur Antwort meist gedulden, aber sie kommt. Hier ist besonders bemerkenswert, dass trotz der starken Belastung in den Pflegeeinrichtungen die Menschen dort Zeit und Muße finden, eine solche Antwort zu begleiten und abzuschicken. Dies ist keine Selbstverständlichkeit und zeigt, wie sehr sich in den Einrichtungen bemüht wird, den dortigen Bewohner/innen unterstützend zur Seite zu stehen.

Ein sehr schönes Beispiel für eine solche entstanden Freundschaft ist eine zweite Studentin der Ruhr-Universität Bochum, Melina Reinnert, die von Beginn an bei der Aktion dabei war und das begleitende Seminar im Sommersemester besucht hat. Auch sie hat im Rahmen der Veranstaltung eine abschließende Ausarbeitung verfasst, in der sie sehr einfühlsam von ihren Erfahrungen aus der Teilnahme berichtet hat (vgl. Reinnert, 2020). Nach zwei vermittelten Personen, die sie ohne Rückantwort anschrieb, schrieb sie einer Frau, von der ich aus dem Pflegeheim die Nachricht erhalten hatte, dass sie nicht mehr in der Lage sei, selbstständig zu antworten. Diese Information hatte die Studentin entsprechend bei der Vermittlung erhalten, gemeinsam mit der Anregung, dem Brief einfache 
Antwortmöglichkeiten beizulegen (für ein Beispiel s. Abb. 13) weiter unten. Und dies funktionierte in dem Fall sehr gut. Es kamen die vorformulierten Fragen mit Antworten zurück. Melina Reinnert schickte weitere Grüße und so entwickelte sich zunächst ein Austausch mit ausführlicheren Briefen der Studentin und kurzen angekreuzten Rückantworten der Pflegebedürftigen. Dann jedoch kam ein paar Wochen später ein ausführlicherer Brief, den die Pflegebedürftige auf Initiative einer Mitarbeiterin des Sozialen Dienstes dieser diktierte. In ihm berichtete sie ausführlicher über sich, schrieb, dass sie eine Augenerkrankung habe und daher die Briefe vorgelesen bekommen müsse und nur mit Unterstützung antworten könne. Zugleich schilderte sie, wie aktiv sie im Wohnheim sei (sie ist u. a. im Bewohnerbeirat aktiv) und wie sehr sie sich jeweils über die Briefe freue. Diesem ausführlicheren Brief folgte etwas später ein Schreiben des Neffen der pflegebedürftigen Frau. In diesem berichtete auch er von der großen Freude, die seine Tante durch die Briefe bekomme und bedankte sich auch im Namen der Familie sehr herzlich für die Kontaktaufnahme und das Engagement. Er selbst - und andere Familienmitglieder - konnten ihre Verwandte nicht mehr besuchen, da sei jedes Zeichen von Aufmerksamkeit auch von fremden Menschen hilfreich. Seit diesem Brief steht die Studentin nun nicht mehr nur mit der Pflegebedürftigen, sondern auch mit ihren Angehörigen in Kontakt. Sie schickte mir zu Weihnachten die folgenden Zeilen:

„Ich stehe immer noch mit M. in Kontakt und habe ihr zu Weihnachten ein kleines Paket geschickt. Auch mit der Familie stehe ich immer noch im Austausch. Sie informieren mich über jeden Schritt sodass ich das Gefühl habe M. schon viele Jahre zu kennen. Ich hoffe, dass diese Brieffreundschaft noch lange hält. Sehr gerne würde ich M. auch einmal besuchen aber durch die aktuelle Lage stellt das eine zu große Gefahr für die Bewohner dar und ich möchte keine Anderen gefährden." (Melina Reinnert)

Ein weiteres Beispiel zeigt die Rückantwort der ältesten Teilnehmerin - mit 104 Jahren. Besonders eindrücklich erscheint hier die Handschrift (Abb. 12):

Wie aus diesen Beispielen bereits ersichtlich ist, wird vielfach die aktuelle Situation thematisiert und der Wunsch geäußert, sich nach Beendigung der Pandemie persönlich kennenzulernen. Auch dies ist aus meiner Sicht ein Zeichen für eine gelungene Kontaktaufnahme verbunden mit der Chance, auch langfristige Beziehungen aufzubauen.

Schließlich soll hier noch ein Beispiel für die bereits an einigen Stellen erwähnte vorformulierte Antwortmöglichkeit angeführt werden. Wie bereits oben angedeutet, ist uns in einigen Fällen durch das Pflegeheim die Nachricht zugegangen, dass die pflegebedürftige Person gerne an der Aktion teilnehmen möchte 


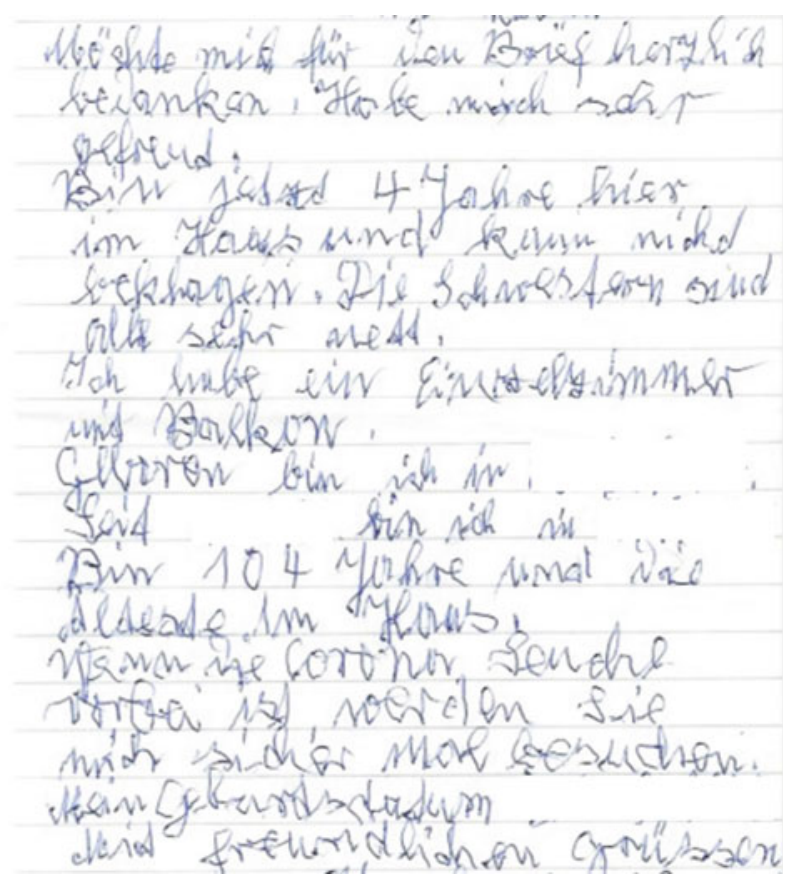

Abb. 12 Brief einer 104 Jahre alten Frau aus dem Pflegeheim

und sich über Briefe freut, voraussichtlich aber nicht in der Lage sein wird, eigenständig zu antworten. Um dennoch zu ermöglichen, dass einerseits die Person einen kleinen Gruß zurücksenden kann und andererseits die Briefeschreiber/in die Bestätigung bekommt, dass ihre Briefe zugestellt und gerne gelesen werden, erging in diesen Fällen der Rat an die jeweiligen zugeordneten Personen, ihrem Brief eine vorformulierte Antwortkarte beizulegen, auf der geschlossene Fragen stehen. So erhält der/die Empfänger/in die Möglichkeit, diese durch Ankreuzen von JA/NEIN auf einfache Art zu beantworten. Ein Beispiel für solch eine Antwortkarte mit erfolgten Reaktionen der pflegebedürftigen Person ist hier zu sehen: (Abb. 13)

Mit dieser Form der Antwortkarten bekamen viele Briefeschreiber/innen Antworten und erfuhren so stückweise vom Leben der anderen Person und konnten sichergehen, dass ihre Briefe ankommen und für Freude sorgen. 
Abb. 13 Vorformulierte Antwortkarte zum Ankreuzen, mit entsprechender Reaktion einer Pflegebedürftigen

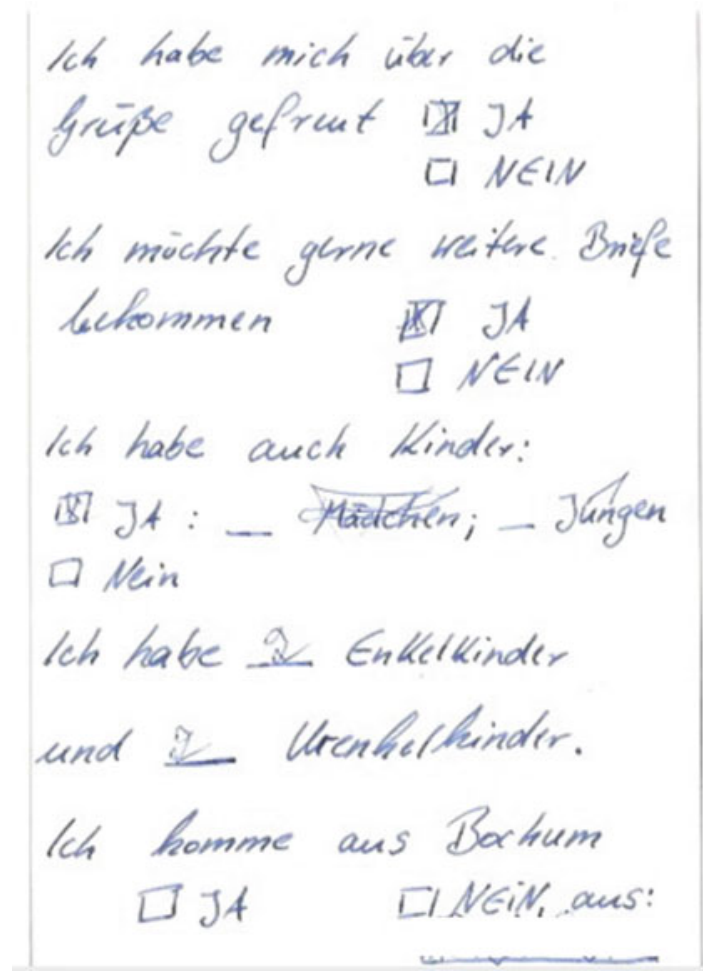

Die hier abgedruckten Impressionen und Fallbeispiele liefern Einblicke in die Aktion „Briefe gegen die Einsamkeit“ und können evtl. einen kleinen Eindruck dessen vermitteln, welche Optionen sich aus diesem intergenerationellen Briefwechsel eröffnen. Ich möchte an dieser Stelle noch einmal auf die Frage der Nachhaltigkeit dieser Aktion eingehen. Zunächst möchte ich dafür festhalten, dass in keinem einzigen Fall eine Rückmeldung kam, dass sich eine angeschriebene Person NICHT über den Gruß gefreut habe ${ }^{8}$. Vielmehr hörten wir aus vielen Pflegeheimen, dass die Briefe sehr freudig begrüßt wurden und teilweise

\footnotetext{
${ }^{8}$ Nur in einem mir bekannten Fall bekam eine Teilnehmerin die Rückmeldung von einer angeschriebenen Frau zurück, dass sie sich zwar über den Brief gefreut habe, aber lieber keine weiteren Briefe mehr bekommen möchte. Als Erklärung schrieb eine Pflegekraft dazu, dass sich die angeschriebene Frau nicht in der Lage sähe, selbst zu antworten und sie es daher als nicht zielführend ansähe.
} 
Gesprächsstoff für mehrere Tage boten. Sei es der Austausch über die Freude beim Erhalt und Lesen, die Überlegung, was und wie zurückgeschrieben werden soll, oder dann der Bericht über die erfolgte Rückantwort. Auch wenn diese ausblieb, blieben in allen Fällen die anderen beiden Punkte bestehen. Vielfach wurde die Aktion von Mitarbeiter/innen der Einrichtungen mitbegleitet und in gemeinsame Schreibaktionen überführt, viele Einrichtungen zeigten sich bei unserer Nachfrage sehr gut über den jeweiligen Stand des Austausches ihrer Bewohner/innen informiert. Dies zeigt zum einen, dass die ursprüngliche Idee der Aktion tatsächlich erfolgreich umgesetzt werden konnte: Wir wollten den isolierten pflegebedürftigen Menschen eine Freude machen und ihnen Aufmerksamkeit schenken. Das ist gelungen und damit ist die Aktion aus meiner Sicht der Organisation bereits erfolgreich. Zum anderen zeigt sich mir, dass auch die Pflegeheime - in diesem Fall meine ich die Mitarbeiter/innen - ihren Anteil an der Aktion leisten und zugleich auch davon profitieren. Sie haben z. T. Zeit und Interesse investiert und wurden dafür mit der Freude der Bewohner/innen und einer schönen Abwechslung belohnt. Einige Einrichtungen meldeten uns auch zurück, dass sie dankbar dafür waren, eine gemeinsame freudige Aktivität für die Bewohner/innen zu haben, da der Alltag in der Zeit des Besuchsverbotes doch für alle sehr schwer und einsam war. Insofern trug diese Aktion bereits Früchte, unabhängig davon, ob sich nun in jedem Fall eine tiefe Brieffreundschaft entwickelt hat.

Werfen wir jedoch nun auch einen Blick auf diese Frage. Wie bereits in meinen Fallbeispielen sichtbar wurde, haben sich Freunde gefunden, die über unterschiedlichste Arten in Kontakt getreten sind und sich gegenseitig kennengelernt haben. Das ist natürlich eine wunderbare Bestätigung, die die Hoffnungen, aus denen heraus die Aktion entstanden ist, erfüllt hat. Dies ist aber selbstverständlich nicht in allen vermittelten Fällen eingetreten. Wie bereits oben ausgeführt, erwies sich auch über die gesamte Gruppe an vermittelten Paaren, dass etwa ein Drittel in einen wie auch immer gearteten Austausch getreten ist und es zu mindestens einem Briefwechsel und auch, wie geschildert, zu tiefem Austausch und echten Brieffreundschaften $\mathrm{kam}^{9}$. Ein weiteres Drittel bekam zunächst keine Antwort

\footnotetext{
${ }^{9}$ Um dies mit einer konkreten Zahl zu untermauern: In dem eingerichteten Moodle-Kurs konnten alle dort eingeschriebenen Briefeschreiber/innen freiwillig ihre und die Antwortbriefe ihrer Brieffreunde hochladen. Diese Möglichkeit nutzten 63 der in dem Kurs eingeschriebenen Personen (dies waren insgesamt 112). Alle luden den ersten Brief zur Kontaktaufnahme hoch. Von diesen 63 luden wiederum 28 eine Rückantwort ihrer/s Brieffreundes/in hoch. Dies bedeutet natürlich nicht, dass alle anderen keine Rückantwort bekamen, sondern nur, dass sie sie nicht zur Verfügung stellten (was ja schließlich auch freiwillig war). Aber diese 28 erhielten sie definitiv. Von einigen weiteren Personen bekam ich persönlich per Mail Rückmeldung zum Status ihrer Brieffreundschaft. Diese gehen entsprechend auch in meine Berechnung ein. Dennoch möchte ich betonen, dass diese Berechnung der Drittel eine ungefähre Näherung ist.
} 
und trat in Kontakt mit mir. Hier erging von mir zunächst der Rat, es mit der oben illustrierten Antwortkarte zu versuchen. Parallel dazu riefen wir in den entsprechenden Pflegeheimen an und erkundigten uns nach dem Stand der Dinge vor Ort. Hier ergaben sich z. T. Informationen, die wir weitergeben konnten, sodass sich ein Teil der Kontakte daraufhin fand bzw. zumindest ein Informationsaustausch stattfand. In den Fällen, in denen die junge Person einen weiteren Kontakt wünschte, vermittelte ich eine zweite Person, die angeschrieben werden konnte. Auch hier gab es logischerweise wieder einen gewissen Prozentsatz, die auch von einer zweiten Person keine Rückantwort bekam und weitervermittelt wurde.

Auch wenn eine fehlende Antwort zunächst für die jungen Briefeschreiber/innen enttäuschend sein konnte, liegt dies in der Natur der angelegten Aktion. Da hier Menschen angeschrieben werden, die pflegebedürftig sind, kann man davon ausgehen, dass sie in irgendeiner Form Einschränkungen aufweisen. Hierbei gilt es zu bedenken, dass gerade das Schreiben eines Briefes eine hohe Konzentration und motorische Fähigkeiten erfordert. Beides kann u.U. bei den angeschriebenen Personen beeinträchtigt sein und damit eine Rückantwort zu einer Herausforderung werden lassen. Wir hatten zwar durch die Anfrage in den Einrichtungen von dort Personen genannt bekommen, die grundsätzlich Interesse an einem Austausch haben, dennoch konnte man auch bei ihnen nicht davon ausgehen, dass sie problemlos in einen schriftlichen Austausch treten können. Dafür sensibilisierte ich die teilnehmenden jungen Personen und klärte über entsprechende Ausführungen, die ich per Mail und über den Moodle-Kurs zur Verfügung stellte, über die Situation in den Pflegeeinrichtungen und die hier geschilderten Einschränkungen der pflegebedürftigen Personen auf. Darüber wollte ich ein Verständnis bei den Personen wecken, die verständlicherweise enttäuscht darüber waren, dass sie auf ihre Grüße keine Antwort bekamen. Vielfach wurde mir von ihnen zurückgemeldet, dass dieses Verständnis eingetreten ist und sie damit zufrieden sind, dass ihre Briefe angekommen sind und zumindest einmalig für Freude gesorgt haben. So sehe ich einen weiteren Beitrag der Aktion darin, eine entsprechende Sensibilisierung und einen genaueren Blick auf die Situation von Pflegebedürftigen und an Pflegeheimen herbeigeführt zu haben. Ein Teil dieser betroffenen Personen beließ es dann in Rücksprache mit mir bei den Kontaktversuchen, einige andere wurden auf eigenen Wunsch weitervermittelt und konnten dann z. T. doch mit der dritten (und in einem Fall sogar vierten) Person in einen Austausch treten. Dies ist für mich wiederum ein Zeichen dafür, wie ernst es auch

Ich habe nicht von jeder Person eine Rückmeldung bekommen und fordere diese auch nicht zwangsläufig und ständig aktualisiert ein. 
die jungen Personen nahmen und mit wie viel Engagement sie an der Aktion teilgenommen haben. Sie wollten auch ihrerseits einen Austausch und freuten sich, wenn dieser dann tatsächlich eintrat. Insofern kann man hier von keiner Einbahnstraße ausgehen, sondern festhalten, dass es für beide Seiten seine sehr schönen und bereichernden Momente hat.

Über das letzte, auch hier nicht ganze Drittel kann ich, wie bereits erwähnt, relativ wenig Aussagen treffen, da ich in diesen Fällen entweder nur wenig oder gar keine Rückmeldung bekommen habe. Auch dies ist durch die Umsetzung der Aktion zu begründen. Es bestand von Anfang an kein Zwang, daran teilzunehmen, oder eine Verpflichtung, Bericht zu erstatten. Dass dies dennoch so vielzählig eingetreten ist, ist für mich aus Sicht der Organisatorin vielmehr ein sehr schönes Zeichen und soll nicht als negativ für die Fälle gedeutet werden, in denen es nicht der Fall war.

Somit bleibt resümierend festzuhalten, dass diese Aktion in vielerlei Hinsicht einen Beitrag geleistet hat und sich dieser nicht leicht in einem Schlagwort zusammenfassen lässt. Es sind Freundschaften entstanden, es ist Freude bereitet worden, es wurde für Gruppen und Einrichtungen sensibilisiert und es wurde gezeigt, dass sich Menschen für andere Menschen interessieren und sie sich an einem Austausch miteinander erfreuen. Und dies, ohne eine weitere Gegenleistung zu erwarten $^{10}$. Somit sehe ich die Aktion Briefe gegen die Einsamkeit als eine sehr schöne Bereicherung und Ergänzung zur Tätigkeit von UnVergessen an.

\section{Das wissenschaftliche Potenzial des Projektes}

Wie bereits in dem obigen Abschnitt ausgeführt, ist sowohl im Hauptprojekt von UnVergessen als auch in der Aktion Briefe gegen die Einsamkeit die Möglichkeit

\footnotetext{
${ }^{10}$ Hier möchte ich eine weitere Besonderheit erwähnen: In dem ersten Informationsschreiben, dass die jungen Briefeschreiber/innen von mir mit der Vermittlung einer Person bekommen haben, habe ich sie darüber aufgeklärt, dass sie die ihnen im Rahmen dieser Aktion entstandenen Portokosten an mich weitergeben und diese erstattet bekommen können. Dies empfand ich als angemessene Geste für ihre Mühe und ja auch tatsächlichen Kosten, da die Idee ja war, dass jeweils ein frankierter Rückumschlag beigelegt werden sollte. Zudem schickten einige auch nicht nur Briefe, sondern Päckchen etc. Als ich dies formulierte, war mir allerdings nicht klar, dass die Aktion eine solche Nachfrage haben würde, und während der Vermittlung von immer mehr Personen und dem entsprechenden Überschlag der Summe wurde mir manchmal etwas bang. Allerdings bedachte ich dabei nicht, aus welchen Gründen die Personen daran teilnahmen. Ihnen ging es ganz anscheinend nicht um Portokosten bzw. die entsprechenden Unkosten. Dies wurde mir allerspätestens im Lauf der letzten Monate klar, in denen keine einzige der Teilnehmer/innen die Kosten bei mir einforderte.
} 
einer wissenschaftlichen Aufbereitung angelegt. In diesem Abschnitt möchte ich zunächst ausgehend von den schriftlichen Daten auf das größte Desiderat der aktuellen gerontolinguistischen Forschung zu sprechen kommen und anreißen, in welcher Weise die unterschiedlichen Projekttätigkeiten hier einen wichtigen Beitrag leisten können.

Im vorherigen Kapitel wurden bereits einige Aspekte beleuchtet, in welcher Weise die Briefwechsel, die im Rahmen der Aktion Briefe gegen die Einsamkeit entstehen, für wissenschaftliche Fragen von Interesse sind. An dieser Stelle möchte ich etwas expliziter auf die gerontolinguistischen Aspekte eingehen. Ein Schwerpunkt in der Erforschung der Sprache des Alters liegt in der Frage, wie sich die Handschrift und die schriftlichen Ausdrucksfähigkeiten im Laufe des Lebens verändern (für einen Einblick in einige der Fragestellungen empfehle ich den Artikel von Walther, 2019). Diese Untersuchungen zur Grafologie überschneiden sich dabei mit patholinguistischen und medizinisch-diagnostischen Fragestellungen, wie z. B. jene nach Beeinflussung der Handschrift durch bestimmte Erkrankungen. So gibt es bspw. Ausführungen dazu, wie die Parkinsonerkrankung typische Veränderungen im Schriftbild auslöst, aus der sich Ansätze der Diagnostik entwickeln lassen (vgl. z. B. Schreier und Bollschweiler, 2014 oder die Berichterstattung von Wagner, 2013 im Deutschlandfunk). Wichtige Hinweise - auch im Bereich der Früherkennung - kann die Handschrift im Fall einer Erkrankung an Multipler Sklerose liefern, und auch im Zusammenhang mit der Alzheimer-Demenz existieren Ansätze, die Handschrift Erkrankter zu analysieren und bestimmte Spezifika zu ermitteln (so zeichnet sich diese durch ein unruhiges Schreiben mit unterschiedlichen Phasen der Schreibgeschwindigkeit aus - einen umfassenderen Einblick dazu liefert Feimer, 2005). Dies zeigt, dass die Handschrift von Belang und wissenschaftlichem Interesse ist. Häufig liegt der Erforschung jedoch eine doppelte Problematik zugrunde:

Zum einen fehlen Untersuchungen dazu, wie sich die Handschrift im Fall des sog. gesunden Alterns verändert und damit die wichtige kontrastive Grundlage, abweichende Veränderungen feststellen und interpretieren zu können. Und zum zweiten existiert bislang keine aussagekräftige Datenbank an diversem Schriftmaterial, das als Grundlage entsprechender Untersuchungen herangezogen werden kann. Dieses Desiderat erklärt auch das erste Problem, da schlicht die Vergleichsgrundlage mit Schriftbildern gesunder älterer Menschen fehlt.

Diese Lücke im Datenmaterial betrifft dabei keineswegs nur die schriftlichen Erzeugnisse, sondern jegliche Form von sprachlichen Daten älterer Menschen. In der gesamten Erforschung gerontolinguistischer Fragen wird immer wieder bemängelt, dass entsprechende Korpora jedweder Materialien fehlen und damit die Forschung schnell an ihre Grenzen stößt (vgl. hierzu z. B. die immer wieder 
geführte Debatte zu Korpora in der CLARe-Community (Corpora for Language and Aging research), die sich speziell aus diesem Grund formiert hat. Einen Überblick darüber bietet: https://wikis.fu-berlin.de/display/clare/HOME und auch die Konferenzhomepage des 4. Treffens: https://www.helsinki.fi/en/conferences/ corpora-for-language-and-aging-research-4).

Dieses Desiderat ist auf vielerlei Weise zu begründen (auch hierzu finden sich schnell entsprechende Ausführungen, ein Blick in die o.g. Seite mit Weiterführungen zu verlinkten Personen, Forschungsausrichtungen und Artikeln vermittelt einen Eindruck), führt jedoch dazu, dass wichtige Forschungsfragen nicht weiterverfolgt werden können. Insofern ist es mehr als relevant, an dieser Stelle anzusetzen und so nicht bloß die eigene Forschung zu ermöglichen, sondern einer ganzen Forschungsgemeinde eine Grundlage zu geben, ihrer Forschung fundiert nachgehen zu können.

Durch die oben dargestellte Konzeption der Aktion Briefe gegen die Einsamkeit erfolgt eine Sammlung von schriftlichen Daten, die meines Wissens bislang einmalig ist. Durch sie werden Briefstücke dokumentiert, die über die reine Unterschrift oder das Abschreiben einzelner Sätze hinausgehen, sondern Einblicke weit über die reine Handschrift hinaus in die schriftlichen Fähigkeiten der Personen erlauben. Durch die Kontakte zu den Pflegeheimen - und auch die Informationen durch die Briefeschreiber/innen selbst - können diese schriftlichen Zeugnisse mit gesundheitlich relevanten Daten abgeglichen werden und so eine Grundlage für ein schriftliches Korpus im gerontolinguistischen Bereich bilden. Bei der Erstellung eines solchen - perspektivisch frei verfügbaren Datenpools bieten sich Kooperationen unterschiedlichster Art an. Da es sich hier vorrangig um deutschsprachige Schriftstücke handelt ist die Vernetzung mit der Germanistik möglich. Kooperationen zu gerontologisch ausgerichteten Forschern bestehen durch meine eigenen Aktivitäten bereits. Auch diese sollten hier ausgebaut werden. Des Weiteren bietet sich die Vernetzung mit pflegewissenschaftlich ausgerichteten Hochschulen an. Auch hier existieren bereits Kooperationen mit zwei Hochschulen (der Hochschule für Gesundheit in Bochum mit Prof. D. A Posenau und der Evangelischen Hochschule Rheinland-Westfalen-Lippe mit Prof. Dr. A. Kuhlmann), die bereits Interesse an einem Ausbau der Tätigkeiten signalisiert haben.

In welche Richtung die schriftlichen Daten genutzt werden können, wird sicherlich die nahe Zukunft und die Aufbereitung der Aktion im Rahmen von Lehrveranstaltungen zeigen. Durch die geplanten studentischen Forschungsprojekte werden sich hier konkretere Perspektiven und Ansatzpunkte für zukünftige Aktivitäten zeigen. 
Die obigen Ausführungen betrafen die perspektivischen Potenziale der schriftlichen Daten. Daneben hat die Projekttätigkeit jedoch bereits seit mehreren Jahren weitere Daten hervorgebracht, die in anderer Hinsicht einzigartig und von höchstem Interesse für mindestens zwei Forschungsbereiche sind. Es handelt sich dabei um die Daten, die im Rahmen des Projektes UnVergessen und der sprachlichen Begleitung von mehrsprachigen Pflegebedürftigen in deutschen Pflegeheimen durch ihrerseits mehrsprachige Studierende gesammelt wurden. Dabei wurden mit entsprechender rechtlicher Absicherung und Einverständniserklärungen von den beteiligten Gesprächspaaren Audioaufnahmen ihrer Gespräche angefertigt und zur wissenschaftlichen Verwendung zur Verfügung gestellt. Diese Aufnahmen, die einen Einblick in eine spontane mündliche Produktion mehrsprachiger Pflegebedürftiger in unterschiedlichen Settings liefern, wurden dabei um gezielte Aufnahmen von Pflegesituationen einerseits und linguistischen Untersuchungen andererseits ergänzt. Auf diese Weise ist ein Gesprächskorpus entstanden, das mittlerweile über $50 \mathrm{~h}$ Aufnahmen enthält. Dabei sind Gespräche enthalten, die jeweils reinsprachig auf Russisch oder Polnisch zwischen Studierenden und Pflegebedürftigen geführt wurden, solche, in denen in unterschiedlicher Quantität auch deutsche Sprachäußerungen auftreten, und ebenso Aufnahmen, die rein auf Deutsch geführt wurden. Neben dialogischen Gesprächen finden sich auch spontane Interaktionen zwischen Pflegebedürftigen und/oder mit Pflegekräften, sodass die Aufnahmen wertvolle Einblicke in den Pflegeheimalltag bieten.

Durch den bereits geschilderten Projektablauf und die Konzentrierung im zweiten Teil auf eigene wissenschaftliche Ausarbeitungen haben die studentischen Projektteilnehmer/innen jeweils eigenständige Untersuchungen konzipiert und durchgeführt. Da diese jeweils durch Aufnahmen dokumentiert wurden, bilden sie einen wichtigen Teil des Korpus. Hier finden sich z. B. Aufnahmen jeweils auf Russisch, Polnisch und Deutsch von Bildbenennungstests, Nacherzählungen von Bildergeschichten in eben jenen Sprachen, das gemeinsame Ausmalen und Benennen von Bildvorlagen, Assoziationstests und auch der Einsatz von Phraseologismenspielen (vgl. hierzu auch die Dokumentation der Ausstellung von UnVergessen $^{\text {PLUS }}$ 2019, einsehbar unter: https://www.un-vergessen.de/berichter stattung, PDF: Dokumentation der Ausstellungseröffnung am 25.06.2019). Diese Aufnahmen können gezielt für entsprechende linguistische Fragen genutzt werden. Einblicke dazu finden sich in den in Teil V dieses Bandes folgenden Ausführungen und Darstellungen der studentischen Forschungsarbeiten.

Die im Rahmen des Projektes erhobenen Aufnahmen von Morgenpflegesituationen umfassen Interaktionen zwischen unterschiedlich sprachigen Pflegekräften mit verschiedenen russischsprachigen Pflegebedürftigen. Hier kommt 
es zu insgesamt drei Konstellationen, die bereits in Teil II dargestellt wurden: rein deutschsprachige Interaktion zwischen deutschsprachiger Pflegekraft und russischsprachigem Pflegebedürftigen, gemischtsprachige Interaktion Russisch, Deutsch und Russisch-Deutsch zwischen deutsch- und russischsprachigen Pflegekräften mit russischsprachigem Pflegebedürftigen und rein russischsprachige Interaktion zwischen russischsprachiger Pflegekraft und russischsprachigem Pflegebedürftigen. Diese Aufnahmen sind meines Wissens unikal und bieten bislang unbekannte Einblicke in den mehrsprachigen Pflegealltag in deutschen Pflegeheimen.

Die auf diese Weise erhobenen Daten bieten eine Möglichkeit der wissenschaftlichen Aufbereitung in Form eines Korpus, der wiederum der Wissenschaft zur Verfügung gestellt werden soll. Dafür ist bereits ein Antrag in Ausarbeitung.

Die Forschungslücke, die mit diesem Antrag gefüllt werden soll, liegt dabei in der Verzahnung von Mehrsprachigkeit auf der einen und Alters- bzw. Pflegeforschung auf der anderen Seite. Beide Disziplinen verfügen für sich über einen umfangreichen wissenschaftlichen Diskurs, weisen aber jeweils einen blinden Fleck auf. Die Mehrsprachigkeitsforschung konzentrierte sich bislang vor allem auf den Bereich des (kindlichen) Spracherwerbs (vgl. im slavistischen Bereich u. a. Anstatt, 2007) und die Phase der Jugendlichen bzw. (jungen) Erwachsenen (wie auch in meiner Dissertation mit russisch-deutschem Fokus, Karl, 2012). Erst in neuester Zeit erwacht ein Interesse an Fragestellungen, die sich mit dem Verlauf der Mehrsprachigkeit über die gesamte Spanne des Lebens beschäftigt (dies zeigt z. B. die Initiierung eines Workshops zu diesen Themen im Frühjahr 2018 an der Ruhr-Universität Bochum oder auch ein Austauschtreffen von interessierten linguistischen Forscher/innen im Januar 2019 in Berlin). Nur sehr vereinzelte Forschung konzentriert sich dabei auf die Frage, welche Auswirkungen von Mehrsprachigkeit im höheren Alter zu beobachten sind. Dennoch finden sich einige Untersuchungen, die die Frage danach aufgreifen, ob Mehrsprachigkeit zu einem kognitiven Vorteil im Alter führt oder eher als doppelte Belastung zu verstehen ist (hier sind die Studien in Bialystok und Sullivan 2017 als richtungweisend hervorzuheben). Welche Prozesse und sprachlichen Erscheinungen jedoch konkret zu beobachten sind und welche unterschiedlichen Ausprägungen der Mehrsprachigkeit im Alter daraus erwachsen, ist bislang ein unerforschtes Gebiet.

Die (linguistisch orientierte) Alters- bzw. Pflegeforschung ist ein an sich noch recht junges Forschungsfeld, das sich überwiegend mit den linguistischen Besonderheiten und Bedürfnissen monolingualer Sprecher/innen auseinandersetzt. In diesem Diskurs finden sich Bestrebungen, größere bislang rein monolinguale Sprachkorpora zu erheben, aufzubereiten und wissenschaftlich nutzbar zu machen 
(vgl. hierzu z. B. die bereits oben erwähnten Tätigkeiten des CLARe-Netzwerkes oder des sog. ILSE-Korpus), bislang existieren jedoch noch keine vollständig annotierten Korpora, die meisten liegen als untranskribierte oder in unterschiedlichem Umfang und Qualität transkribierte Gesprächsaufnahmen vor. Korpora, die Aufnahmen von mehrsprachigen Sprecher/innen im Alter beinhalten, existieren aktuell nicht.

Eine ähnliche Fokussierung auf monolinguale Personen ist im Bereich der Pflegekommunikation zu beobachten. Hier liegen mit Studien von z. B. Posenau (u. a. 2014) oder Sachweh (u. a. 2006) wichtige Grundlagen vor, in welcher Weise die Kommunikation mit kognitiv gesunden und beeinträchtigten (v.a. dementen) Pflegebedürftigen abläuft. Posenau (2014) hat dabei ein monolinguales Gesprächskorpus erstellt, welches für kontrastive Arbeiten herangezogen werden kann. Ausarbeitungen zum mehrsprachigen Pflegealltag liegen bislang nur vereinzelt vor (vgl. hierzu z. B. Plejert et al., 2017) und zeigen vor allem die Desiderata in diesem Bereich auf.

Durch die Erstellung eines Korpus mehrsprachiger Interaktion im Pflegebereich soll eben jener beiderseitige blinde Fleck aufgegriffen werden. Die Arbeit rund um diese Erstellung sieht drei geplante Schwerpunkte vor. Der eine Schwerpunkt, auf dem alle weiterführende Arbeit basiert, ist die Aufbereitung der o.g. Daten, insbesondere Aufnahmen von Gesprächen mit mehrsprachigen Pflegebedürftigen zu einem wissenschaftlich zu nutzenden und aufbereiteten Korpus. Hier liegt die Hauptarbeit in der Transkription und Annotation der Daten. Die Aufbereitung der Daten soll über EXMERaLDA und in enger Absprache mit dem Archiv für gesprochenes Deutsch erfolgen, über welches das dann fertige Korpus zur Verfügung gestellt werden soll. Dabei ist, je nach endgültiger Ausrichtung des Korpus, eine Implementierung entweder in den Bereich der Gesprächskorpora als Subkorpus „Pflegekorpus“ (bei entsprechendem Ausbau durch monolinguale Probanden bzw. Andockung an das Korpus von A. Posenau) oder in die Korpora zu Mehrsprachigkeit und Spracherwerb angedacht. Die Bereitstellung eines solchen Korpus ist eine unerlässliche Grundlage für alle Arten von weiterführender linguistischer Forschung in diesem Themenbereich.

Der zweite Schwerpunkt soll im Bereich der Pflegekommunikation (und dort der Gesprächsanalyse) liegen. Hier sollen die bislang zur Verfügung stehenden Gespräche zwischen Pflegebedürftigen und Pflegekräften systematisch analysiert werden und - im besten Fall - für Ausbildungszwecke aufbereitet werden. Hier soll u. a. der Frage nachgegangen werden, wie a) die Kommunikation unter mehrsprachigen Bedingungen abläuft und b) konkrete altersbedingte Krankheiten (v.a. Demenz) die Kommunikation prägen und in der Kombination von a) und b) daraus ggf. erwachsende Kommunikationsprobleme abgemildert werden 
können. Für die beiden genannten Schwerpunkte steht Prof. Dr. A. Posenau von der Hochschule für Gesundheit als Experte zur Verfügung.

Der dritte Schwerpunkt liegt im Bereich von spezifisch linguistisch ausgerichteten Fragestellungen. Auch hier sollen die dann aufbereiteten Daten genutzt bzw. diese im Rahmen des Projektes UnVergessen systematisch ausgebaut und weiter erhoben werden. Dabei soll vorrangig untersucht werden, wie der Sprachstand von demenziell und nicht demenziell erkrankten Pflegebedürftigen mit und ohne Migrationshintergrund in den entsprechenden Sprachen zu beschreiben ist und wie sich dieser über den Projektverlauf entwickelt. Dies soll unter Einsatz von mehreren Erhebungsmethoden erreicht werden - u. a. Bildbenennungsaufgaben, Nacherzählung von Bildergeschichten, Assoziationstests, Satzwiederholungsaufgaben, die zu mehreren Zeitpunkten im Laufe der Projektteilnahme erhoben werden und somit eine Verlaufsperspektive ermöglichen. Diese punktuellen Daten sollen dabei ergänzt werden um die vorhandenen freien Gesprächsaufnahmen mit denselben Personen.

Neben diesen skizzierten wissenschaftlichen Aufbereitungsmöglichkeiten bieten sich vielerlei praktisch orientiertere Ausarbeitungen an. Hier sind bereits in der Kooperation mit Prof. Dr. A. Posenau pflegewissenschaftliche Ausrichtungen angelegt. Durch die Verankerung des Projektes in den Pflegeheimen lassen sich vielerlei übergreifende Projekte andenken, die direkt in der Praxis erprobt werden können. Hier möchte ich stellvertretend für solch einen Ansatz einen kleinen Einblick in eine aus der Projektarbeit entstandene Idee und deren Umsetzung im Pflegeheim geben. Es handelt sich um die Entwicklung und Erprobung eines von uns als Sprachenkörper bezeichneten Bildes, dessen Ziel es ist, die mehrsprachige Pflege für deutschsprachige Pflegekräfte zu vereinfachen. Dies soll in Form eines am Ende in mind. DIN-A3-Format ausgedruckten Plakats geschehen, auf dem ein menschlicher Körper möglichst groß und detailliert abgebildet und möglichst viele der sichtbaren und für die Pflege relevanten Körperteile und Bekleidungsstücke jeweils auf Deutsch und der zweiten Sprache des/r konkreten Pflegebedürftigen beschriftet sind.

Die Idee für diesen Sprachenkörper entstand während eines Besuches von Yvonne Behrens - damals wissenschaftliche Mitarbeiterin des Projektes - in einem der kooperierenden Pflegeheime im Rahmen eines Erstkontakts mit einem Pflegebedürftigen mit Schädel-Hirn-Trauma. Der Pflegebedürftige war ein russischsprachiger Mann, der kaum (mehr?) Deutsch sprach und insgesamt infolge seines Traumas sehr eingeschränkt war. Von Beginn des Besuches an hat er unterschiedliche Körperteile auf Russisch und Deutsch wiederholt und dabei auf seine eigenen jeweils passenden Körperteile gezeigt. Dies nahm einen großen Teil der Interaktion mit ihm ein. $\mathrm{Zu}$ diesem scheinbaren Mantra passend hatte er in seinem 
Zimmer die Zeichnung eines Mannes hängen, dessen Körperteile auf Russisch und Deutsch beschriftet waren. Das Pflegepersonal erzählte auf Nachfrage, dass der Bewohner die Zeichnung mit einer Pflegekraft erstellt und aufgehängt hätte.

Und in diesem Moment war eine Idee für unser Projekt geboren: Könnte man nicht ein solches Bild von Personen anfertigen, auf denen nicht bloß Körperteile, sondern weitere wichtige Begriffe der Morgenpflege, wie z. B. Kleidungsstücke eingezeichnet und direkt in der Sprache der/s jeweiligen Bewohners/in und auf Deutsch gut lesbar eingezeichnet sind? So hätte im Bedarfsfall ein deutschsprachiges Pflegepersonal ein direkt verfügbares „Wörterbuch“ vor sich, auf das es im Zweifelsfall während der Interaktion mit dem/r anderssprachigen Pflegebedürftigen zurückgreifen kann. Da dieses bildlich funktioniert und nicht wie im klassischen Sinne ein Suchen nach einem Wort in Listen ist, war die Vorstellung damit verbunden, dass ein Suchen und Finden des jeweils notwendigen Wortes in der direkten Situation einfacher und damit schneller funktioniert. Unser Ziel war es, ein solches Bild zu erstellen, das klar genug gezeichnet und beschriftet ist, dass es im Zimmer anderssprachiger Pflegebedürftiger aufgehängt werden und bei Bedarf in Pflege- bzw. jeglichen Kommunikationssituationen hilfreich zur Seite stehen kann. Dabei ging es uns jedoch nicht nur um das Endprodukt, sondern auch um die Frage danach, wie die Gestaltung des Bildes und die Beschriftung aussehen soll. Hier entschieden wir uns dafür, dass wir die Pflegebedürftigen aktiv einbinden und daraus eine Interaktionssituation gestalten wollten. Nach entsprechenden weiteren Überlegungen und Suche nach geeigneten Vorlagen fiel die Wahl auf eine einfach gehaltene Zeichnung, die die Umrisse eines weiblichen und eines männlichen Körpers darstellt, ohne zu sehr in individuelle Details, Alters- oder auch deutliche Geschlechtsmerkmale zu gehen. Sie sollte zugleich aber freundlich und nicht zu unbelebt wirken. Nach diesen Vorstellungen erstellte uns Philippe Wolk eine Vorlage für unser Ausmalbild. Zur Illustrierung folgt hier die weibliche Figur (Abb. 14):

Diese Vorlage nahmen die studentischen Teilnehmer/innen bei einem ihrer Besuche in die Pflegeheime zu ihren begleiteten Personen mit und baten diese, die Person auf dem Bild auszumalen. Dabei wurde bei männlichen Bewohnern eine männliche Vorlage, bei weiblichen eine weibliche zur Verfügung gestellt. Die Aufgabe wurde dabei so formuliert, dass die Bewohner/innen zum einen die Person ,anziehen“ sollten und zum anderen so viele Körperteile und Kleidungsstücke wie ihnen bekannt und relevant erschienen nennen sollten. Zunächst wurde ihnen dabei offengestellt, auf welcher Sprache dies geschehen sollte, im Anschluss daran sollten die Studierenden jedoch explizit danach fragen, ob das jeweilige Wort auch in der anderen Sprache bekannt sei. Auf diese Weise kam eine Interaktion zustande, in deren Rahmen die Bewohner/innen zeichneten und 
Abb. 14 Ausmalvorlage des weiblichen

Sprachenkörpers, Graphik

P. Wolk

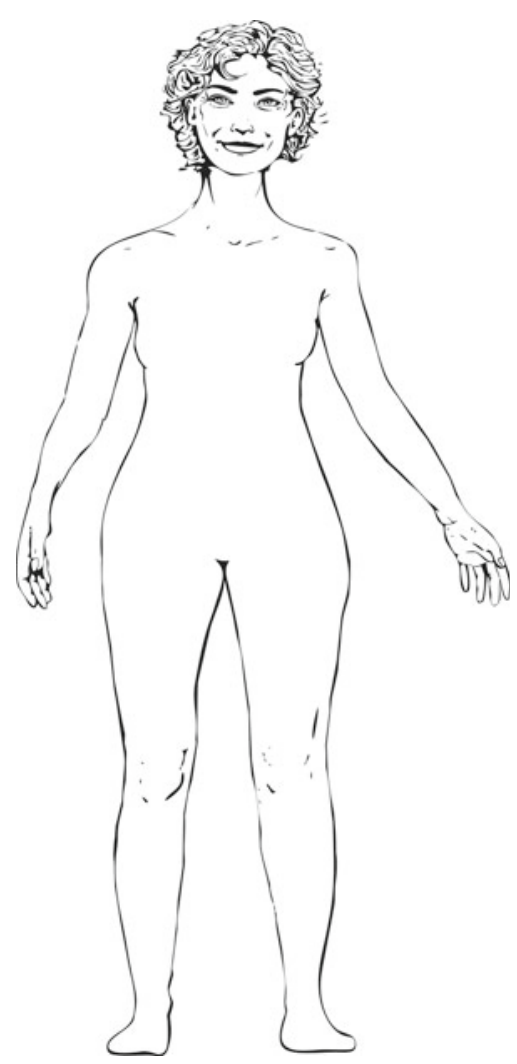

sprachlich tätig waren. Am Ende stand ein individuell ausgemaltes Bild einer Person, die im letzten Schritt eine Beschriftung ihrer Körperteile und Kleidungsstücke in zwei Sprachen erhielt. Da in den meisten Fällen die Bewohner/innen nicht mehr aktiv bzw. gewandt schreiben können - geschweige denn in beiden Sprachen - hat dies in der Regel der/die Student/in übernommen. Der/die Bewohner/in diktierte häufig das Wort, in manchen Fällen ergänzte der/die Student/in das Wort in der zweiten Sprache. Die Interaktion wurde aufgezeichnet und steht weiteren Auswertungen zur Verfügung. Hier könnte bspw. der Frage nachgegangen werden, welche der Körperteile und Kleidungsstücke mit welcher Sicherheit und Selbstständigkeit genannt und in welche der Sprachen zuerst bzw. überhaupt genannt wurden. Dies sind Einblicke in den spontanen produktiven Wortschatz 
bilingualer, meist demenziell veränderter Pflegebedürftiger, die sehr selten zu finden sind. Diese - wiederum linguistisch ausgerichtete - Forschungsfrage stand bei der Erstellung der Sprachenkörper jedoch nicht im Vordergrund. Vielmehr ging es darum, am Ende eine Hilfestellung zu haben, die im Pflegealltag von deutschsprachigen Pflegekräften verwendet werden kann. Damit war auch klar, dass die Beschriftung der Körperteile praktischerweise sowohl auf Deutsch als auch in der jeweiligen Sprache der/s Bewohnerin/s sein sollte. Die Idee war ja gerade, dass die Personen auf die Bezeichnung der jeweiligen Körperteile und Kleidungsstücke in beiden Sprachen zugreifen können sollen und damit für eine gegenseitige Verständigung gesorgt werden sollte. Damit war auch die Hoffnung verbunden, dass deutschsprachige Pflegekräfte die entsprechenden Wörter in der Sprache der/s Bewohnerin/s einsetzen und diese darüber besser angesprochen werden können. Evtl. könnte sogar die Aufmerksamkeit über die Verwendung der vertrauten Sprache geweckt und damit eine bessere Aktivierung erzielt werden. Also musste in der Konsequenz die Beschriftung auf dem Bild so gestaltet sein, dass sie auch jemand lesen und ohne weitere Kenntnisse der jeweiligen Sprache aussprechen können muss. Damit ging einher, dass für die russischen Wörter nicht auf die kyrillische Schrift, sondern auf eine sehr nah an der entsprechenden Aussprache des Wortes orientierte Umschrift mit lateinischen Buchstaben zurückgegriffen wurde. Dabei wurden alle orthografischen Regeln missachtet und nur die Lautlichkeit und beste Annäherung mithilfe der deutschen Orthografie zugrunde gelegt. Somit wurde bspw. aus dem russischen Wort für Kopf голова - wissenschaftlich transliteriert golova - die an der Aussprache orientierte Darstellung galawa. Die Unterstreichung zeigt hier die betonte Silbe an.

Ein solcher Sprachenkörper wurde in Interaktion mit mehreren russisch- und polnischsprachigen Pflegebedürftigen erstellt, einen mit chinesischer Beschriftung erstellten wir mit der Unterstützung einer chinesischsprachigen Studentin ohne den entsprechenden Bewohner, da dieser aufgrund seiner starken Einschränkung dazu nicht mehr in der Lage war. Das Endprodukt wurde im Anschluss im Zimmer der pflegebedürftigen Person aufgehängt und konnte bei Interesse und Bedarf vom Pflegepersonal eingesetzt werden. Ein Beispiel für eine angezogene und auf Russisch und Deutsch beschriftete Frau ist hier zu sehen (Abb. 15):

Natürlich interessierte uns dabei, ob und wenn ja, wie das Pflegepersonal tatsächlich auf den erstellten Sprachenkörper zurückgreift. Dafür führten wir in einem kooperierenden Pflegeheim exemplarische Aufnahmen der Morgenpflege vor dem Aufhängen des Sprachenkörpers und danach durch. Zusätzlich dazu befragten wir Pflegekräfte in Einzelinterviews zur Sinnhaftigkeit des Sprachenkörpers. Ich möchte hier auf eine detaillierte Auswertung dieser Daten verzichten. Eine Aufbereitung mit entsprechend detaillierter Darstellung fand in Form von 
Abb. 15 Ein exemplarischer weiblicher russisch-deutscher Sprachenkörper

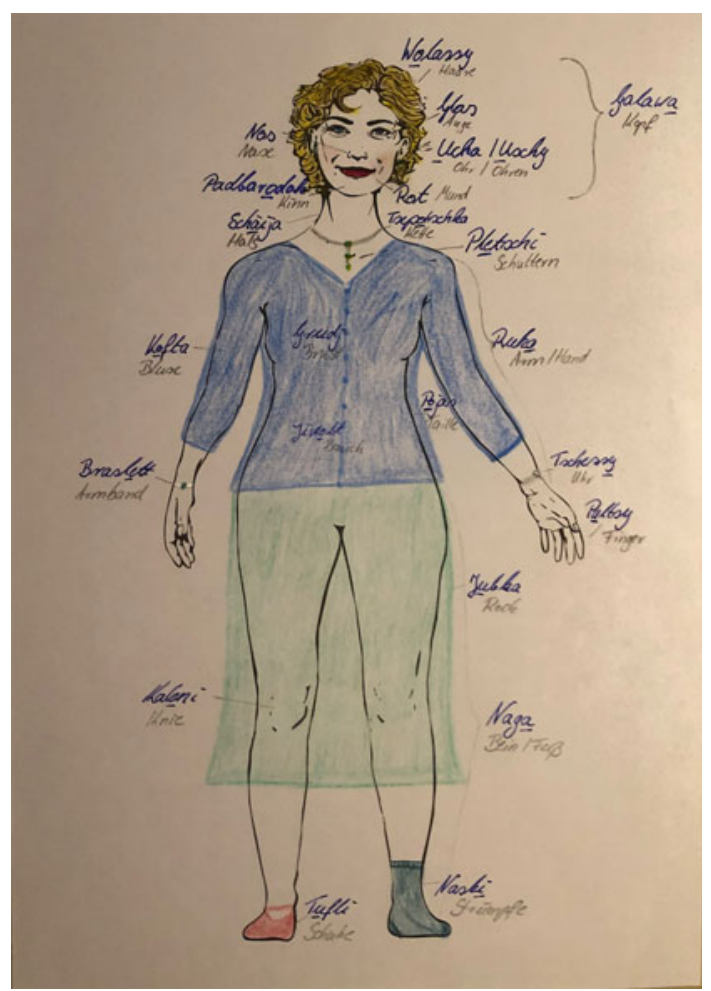

zwei Vorträgen statt (gemeinsam mit Yvonne Behrens, vgl. Dortmund 2019 und Berlin 2019), eine Ausarbeitung in Form eines Artikels befindet sich in Vorbereitung. Ich möchte an dieser Stelle lediglich darauf verweisen, dass die Aufnahmen durchaus Hinweise auf den Sprachenkörper enthalten (er wurde damit also definitiv von den Pflegekräften wahrgenommen), es jedoch offen bleibt, ob er im an sich angedachten Sinne Verwendung finden kann. Die Morgenpflege ist, wie bereits im ersten Teil dieses Bandes dargestellt, ein stark ritualisierter und zielorientierter Ablauf von einzelnen Pflegehandlungen, die jeweils zwischen vertrauten Pflegekräften und Bewohner/in eingespielt sind. Solche Routinen zu durchbrechen und neue sprachliche Strategien zu implementieren, bedarf viel Vorbereitung, Begleitung und Nachbereitung. Diese konnten und wollten wir mit dieser ersten praktischen Erfahrung nicht leisten, wäre aber ein mehr als geeigneter Ansatz, eine breiter und zeitlich länger angelegte Folgestudie ins Leben zu rufen. Aus den 
Interviews mit den Pflegekräften bekamen wir wertvolles Feedback, wie sowohl der Sprachenkörper noch verbessert werden (welche Körperteile und Kleidungsstücke fehlen bzw. evtl. überflüssig sind) als auch eine geschicktere Aufklärung über die Möglichkeiten der Verwendung im Pflegealltag aussehen kann. Auch diese Erfahrungen warten darauf, in eine detailliertere Studie übernommen zu werden.

Die Ausführungen dieses Abschnittes sollten zeigen, welche Potenziale in der bisherigen Projekttätigkeit verborgen liegen und auf welche Weise sie perspektivisch genutzt werden können und sollen. Durch die gesellschaftliche Relevanz des Themas bietet sich der Wissenschaft die Möglichkeit, zu einem konstruktiven Diskurs beizutragen.

\section{Eindrücke aus Sicht einer Lehrenden: Förderung sozialen Engagements, Persönlichkeitsbildung und vieles mehr}

Im normalen universitären Alltag sammelt man als Lehrende vielerlei Erfahrungen. Diese sind geprägt durch die Unterschiedlichkeit der Veranstaltungsformen, die Varianz der Themen und natürlich vorrangig durch die Individualität der Studierenden. Häufig steht dabei in den fachwissenschaftlichen Veranstaltungen die Vermittlung des Wissens im Vordergrund, wenngleich parallel dazu, z. B. über den Einsatz verschiedener Sozialformen und Unterrichtsmaterialien, andere Kompetenzen (wie z. B. soziale, Medienkompetenz u.v.a.) erworben werden. In solch einer Fokussierung laufen diese wichtigen und auf die Berufswelt vorbereitenden Kompetenzen häufig, v.a. für die Studierenden unbemerkt nebenher, tendenziell geraten sie eher selten - meist in den Fällen, wenn etwas nicht ganz glatt läuft - ins Bewusstsein von Lehrenden und Lernenden.

Dies gestaltet sich in der Begleitung des Projektes UnVergessen genau umgekehrt. Hier steht die Ausrichtung auf soziales Engagement von Beginn an im Zentrum und zieht sich als roter Faden durch alle Teile der Projektarbeit. Wie nebenbei erwerben die Teilnehmer/innen den notwendigen fachlichen Hintergrund und wenden diesen in der Praxis an. Aus dem praktischen Tun heraus entdecken sie neue Leerstellen und entwickeln daraus Fragestellungen, die sie wiederum zurück in die Welt der Wissenschaft führen. Auf diese Weise entsteht ein hermeneutischer Zirkel, der Wissenschaft, Praxis und soziales Engagement verbindet.

Was bedeutet hier jedoch soziales Engagement, und wie zeigt sich dieses? Logischerweise steht im Fokus der Projektarbeit die Auseinandersetzung mit 
und das Engagement für pflegebedürftige, meist ältere Menschen im Pflegeheim. Dieses zeigt sich dabei primär in der praktischen Begleitung der jeweiligen Pflegebedürftigen. Hier sind soziale Kompetenzen gefragt, die über das normale universitäre Miteinander hinausgehen. Die wohl wichtigsten Besonderheiten in dieser Art des Beziehungsaufbaus sind dabei der intergenerative Austausch und die Auseinandersetzung mit Pflegebedürftigkeit und dem Alltag im Pflegeheim. Diese beiden praktisch erlebten Komponenten trifft man so selten in anderen universitären Fachveranstaltungen. Diese fordern dabei die Studierenden auf vielfältige Art, so gilt es z. B. jeweils eine ausgeglichene Balance zwischen Verständnis, Nachsicht, aber auch eigener Meinung zu finden, wenn sich in Gesprächen mit dem Vertreter der anderen Generation Differenzen offenbaren. Dies kann u. a. in Fragen der politischen Gesinnung oder auch in der Reflexion der Geschichte auftreten. Hier ist ein ganz besonderes Feingefühl gefragt, wie es einem gelingt, den Gesprächspartner nicht vor den Kopf zu stoßen, aber dennoch sich und seinen Standpunkten treu zu bleiben.

Die zweite Besonderheit liegt im Bereich der Pflegebedürftigkeit, mit der viele der Teilnehmer/innen über das Projekt erstmals in eine tiefere Auseinandersetzung kommen. Hier sind die Studierenden gefordert, sich mit der Institution, dem Alltag und den Abläufen im Pflegeheim vertraut zu machen und dort Verständnis in Situationen zu üben, die von außen zunächst befremdlich wirken können. Zudem sehen sich die Teilnehmer/innen mit der Pflegebedürftigkeit einer speziellen Person konfrontiert, lernen ggf. ein bislang neues Krankheitsbild mit entsprechenden Auswirkungen auf den Alltag kennen und müssen einen Weg finden, damit umzugehen. Dies trifft v.a. in den Fällen zu, in denen eine Person begleitet wird, die an Demenz erkrankt ist. Hier gilt es, sich mit den Auswirkungen der Krankheit auf die Kognition und die Kommunikationsfähigkeit vertraut zu machen und neue Wege zu finden, mit einer Person in Kontakt zu treten. Im Spiegel der Kommunikation mit einer an Demenz erkrankten Person werden dabei Mechanismen der Gesprächsführung, wie z. B. der an sich automatische Wechsel zwischen Sprecher/in und Hörer/in oder die Einbettung des Gesprächs in ein geteiltes Vorwissen klar, die man in normalen Fällen nicht hinterfragt und höchstens von ihnen in linguistischen Theorien im Rahmen der Pragmatik gehört hat. Hier wird diese Theorie greifbar - in dem Moment, wo sie nämlich nicht mehr funktioniert und durch ihr Fehlen die Lücken im Gespräch oder der nicht mögliche Rückgriff auf gemeinsame Erinnerungen offenbar werden.

Diese beiden Aspekte geben einen Eindruck dessen wieder, in welchen neuen Bereichen sich die studentischen Teilnehmer/innen zurechtfinden müssen und welche kommunikativen, intergenerativen und sozialen Kompetenzen dabei erforderlich sind. Durch die Entscheidung der Projektteilnahme ist den Studierenden 
der Fokus auf das soziale Engagement bewusst, die Reichweite der Erfahrungen offenbart sich dabei jedoch meist erst im Verlauf des Projektes. Dies liegt u. a. auch darin begründet, dass in der Konzeption ein großer Schwerpunkt auf den gegenseitigen Austausch, die Reflexion der Erlebnisse und die Aufarbeitung in der Gruppe gelegt wird. In den Seminartreffen berichten die Studierenden jeweils von ihren Begegnungen und Erfahrungen im Pflegeheim. Da dieser Austausch als wichtiges wiederholendes Element in jeder Sitzung ab dem Moment der praktischen Arbeit gepflegt wird, gelingt es den Studierenden sehr schnell, sich in der Gruppe zu öffnen und von ihren z. T. sehr persönlichen Erlebnissen zu berichten, gezielt Probleme anzusprechen und über schwierige Momente zu reflektieren. Dadurch, dass jeder in der Gruppe in einer sehr vergleichbaren Situation ist, entstehen sehr schnell ein Zusammenhalt und ein geschützter Raum, in dem es möglich ist, auch über Probleme, Sorgen und Ängste zu sprechen. Auf diese Weise werden ebenfalls soziale Erfahrungen gemacht: Zusammenhalt in der eigenen Gruppe, Austausch über Probleme, Aufbereitung von schwierigen Situationen und gegenseitige Empathie.

Aus Sicht einer Lehrenden ist es etwas Besonderes, diesen Prozess zu begleiten und zu beobachten. Wo sich zu Beginn einer Projektrunde fremde Menschen treffen, lässt sich wöchentlich beobachten, wie ein Zusammengehörigkeitsgefühl zwischen ihnen entsteht. Spätestens ab dem Moment, in dem alle von dem ersten Treffen mit ihrer Person im Pflegeheim berichtet haben, ist das Eis gebrochen. Den Berichten der Anderen wird in einer Weise aufmerksam gefolgt, die kaum in anderen Veranstaltungen auftritt, häufig entwickeln sich spontane Diskussionen und tiefe Aufarbeitungen zu einzelnen Berichten, die z. B. in der Analyse von Großeltern-Enkel-Beziehungen münden. Oder aber auch in der Frage danach, wie eigentlich Beziehungen aufgebaut werden, welche Rolle die Sprache dabei spielt und wie unter erschwerten Bedingungen Kleinigkeiten auf einmal eine besondere Relevanz erfahren. In jeder bislang begleiteten Projektrunde hat sich ein ganz eigenes und zugleich sehr tiefes Gruppengefühl eingestellt. Dies zeigt sich an vielen Stellen, wie z. B. in der bereits oben dargestellten Möglichkeit, sich in der Gruppe zu öffnen und von den eigenen Problemen zu berichten, der besonderen Stimmung in den Gruppentreffen, in der rückblickenden Evaluation der Teilnahme am Projekt und nicht zuletzt auch an dem über die Teilnahme am Projekt hinausgehenden Interesse aneinander und an dem weiteren Projektgeschehen. Die Entstehung des Alumni-Netzwerkes ist ein Beweis dafür, das weitergehende Engagement z. B. in Form der Beteiligung an diesem Sammelband oder auch die bereits dargestellte Unterstützung einzelner Pflegeheime zu Zeiten von Corona sind es ebenso. 
Die Begleitung dieses Prozesses stellt mich neben den schönen Erfahrungen zugleich immer wieder vor neue Herausforderungen, für die es Wege zu suchen gilt, sie zu lösen. Mein Ziel ist es dabei, den Teilnehmer/innen einen geschützten Raum zur Verfügung zu stellen, in dem sie sich austauschen und auch Hilfe und Unterstützung finden können. Um dies zu erreichen, werden in der Gruppe Gesprächstechniken eingeübt (wie z. B. die Methode der kollegialen Beratung in kleineren Gruppen), aber auch individuelle Beratungsangebote geschaffen. Diese umfassen die Begleitung durch die Mentor/innen (die ehemaligen Projektteilnehmer/innen), die Sprechstunde der Alumni sowie der persönliche Austausch mit mir. Ergänzend stehen in besonderen Fällen externe Angebote zur Verfügung, an die im Notfall vermittelt werden kann. Eine wichtige Komponente in der Begleitung übernimmt zudem auch das jeweils private Netzwerk der Teilnehmer/innen. Hier wird vielfach berichtet, dass Situationen in Gesprächen mit Familie und Freunden aufbereitet wurden und so ein Umgang damit gefunden werden konnte. Diese Erfahrungen führen oft dazu, dass auch diese Netzwerke bewusst wahrgenommen und in ihrer Wichtigkeit geschätzt werden.

Im Normalfall sind diese Angebote ausreichend und werden bewusst in Anspruch genommen und sehr geschätzt. Dort, wo das Gefühl entsteht, dass einzelne Teilnehmer/innen mehr Unterstützung brauchen, ist durch die Kleinheit der Gruppe und den direkten Kontakt gewährleistet, dass punktuell individuelle Unterstützung erfolgen kann.

Dennoch kommt es in der Begleitung zu teilweise emotionalen Momenten, die es besonders zu begleiten gilt. Dies betrifft z. B. die ständige Präsenz von Krankheit und zu erwartendem Lebensende. Die Auseinandersetzung mit dem Tod ist in diesem Projekt inhärent und bedarf auch entsprechend einer Thematisierung in der Gruppe. So ist mittlerweile die Thematik des Todes zu einem festen Bestandteil des Vorbereitungsseminares geworden, der wir uns über Einzelfallschilderungen ehemaliger Teilnehmer/innen und dem freiwilligen Austausch eigener Erfahrungen nähern. So wird das Bewusstsein dafür entwickelt, dass es jederzeit eintreten kann, dass sich der Gesundheitszustand der begleiteten Person verschlechtert. Es kommt tatsächlich häufiger vor, dass einzelne Pflegebedürftige im Krankenhaus sind, und leider gab es auch im Laufe der knapp fünf Projektjahre einige Todesfälle. Diese traurigen Nachrichten treffen alle Projektteilnehmer/innen, besonders natürlich die jeweilige begleitende Person. Eine solche Situation fordert viel von allen Beteiligten und ist dabei von sehr vielen, z. T. kaum zu beeinflussenden Faktoren abhängig, wie z. B. die Frage danach, wer wen über das Ableben informiert und in welcher Form dies geschieht. 
Wenn im Laufe einer aktiven Projektteilnahme ein/e Bewohner/in verstirbt, übernimmt eine wichtige Rolle das jeweilige Pflegeheim, mindestens in der Weitergabe der entsprechenden Information. In jeder Einrichtung steht im Rahmen der Kooperation ein Ansprechpartner zur Verfügung, der sich um die Belange der Studierenden kümmert und z. T. sehr intensiv mit ihnen im Austausch steht. Die Begleitung durch sie umfasst dabei eine erste Einführung in das jeweilige Pflegeheim, die Abläufe und das Team. Daneben wird das erste Kennenlernen mit der pflegebedürftigen Person begleitet. In vielen Fällen steht auch im weiteren Verlauf ein regelmäßiger Austausch in Form von direkten Gesprächen oder durch die Möglichkeit eines solchen Gespräches. Die Ansprechperson kümmert sich somit um den möglichst reibungslosen Ablauf der Besuche und hält bzw. sucht im Notfall den Kontakt zu den studentischen Teilnehmer/innen, um z. B. auch Informationen über Krankenhausaufenthalte o.ä. zu überbringen. Dieser Ablauf funktioniert in den allermeisten Fällen sehr gut. Einige der zuständigen Personen in den Pflegeheimen interessieren sich dabei ihrerseits sehr rege für das psychische Wohlergehen der studentischen Teilnehmer/innen und laden sie zu regelmäßigen Austauschtreffen ein. Einige Einrichtungen haben zusätzlich Angebote im Bereich der Seelsorge, die auch den Studierenden zur Verfügung stehen. Durch die regelmäßigen Besuche im Pflegeheim entstehen darüber hinaus Kontakte zu den Pflegekräften und Mitarbeiter/innen im Heim, die ebenfalls dem Austausch dienen. So entsteht auch hier ein vielfältiges neues Netzwerk, das im Zweifelsfall helfen kann.

In einigen der bisherigen Todesfälle hat sich dieses Netzwerk als hilfreich erwiesen. Die studentischen Teilnehmer/innen wurden von ihrer Ansprechperson sehr einfühlsam telefonisch informiert, häufig erfolgte eine parallele Benachrichtigung der Projektmitarbeiter/innen. Gemeinsam gelang so eine Aufbereitung und auch ein Abschiednehmen. Als Trost stand hier die Erinnerung und die Bewusstmachung, dass die gemeinsamen Momente in den letzten Lebenswochen für die Person eine große Bereicherung waren. In anderen Fällen kam es jedoch leider auch zu Situationen, die für die studentischen Teilnehmer/innen belastender waren. Dies betraf in einem Fall den Tod einer begleiteten Person nach Projektende, in zwei weiteren während der Corona-Einschränkungen. In einem Fall, von dem Dorothea Laszczak als betroffene Teilnehmerin im folgenden Teil dieses Bandes berichtet, verstarb die Person kurz nach dem offiziellen letzten Besuch. Die Studentin, Frau Laszczak, hatte jedoch versprochen, sie nach Projektende noch einmal zu besuchen und von den Ergebnissen ihrer Forschung zu berichten. Bevor es dazu kam, hörte sie jedoch von einer anderen Projektteilnehmerin, die 
einen Bewohner der Einrichtung noch aktiv begleitete, von dem Tod ihrer besuchten Person. Dass dies Frau Laszczak besonders bewegte, ist wohl verständlich, ihre Gefühle und Auseinandersetzung damit schildert sie in ihrem Beitrag.

In den beiden anderen Fällen lag eine jeweils vergleichbare Situation vor: Die Studentin, bzw. ehemalige Studentin, die in Absprache mit allen Beteiligten noch regelmäßig und bereits über einen sehr langen Zeitraum ihren Bewohner besuchte, erfuhr bei einem geplanten Besuch unten an der Pforte der Einrichtung davon, dass die Person gestorben sei. Unabhängig davon, in welcher Form diese Nachricht im konkreten Fall übermittelt wurde, kann man sich leicht ausmalen, welche emotionale Reaktion diese bei den Beiden auslöste. Immerhin waren sie in dem Glauben dorthin gefahren, ihre Person zu besuchen. Die eine Studentin war sogar direkt davor in Russland gewesen und hatte eigens für ihren Bewohner kleine Geschenke mitgebracht. Zu der grundsätzlichen Trauer kommen die unangenehme Gesprächssituation für beide Seiten und der situative Schock hinzu. In beiden Fällen war es eine Erfahrung, die Aufarbeitung bedurfte und den Verlust der Person bzw. die mit dieser gesamten Situation verbundenen traurigen Gefühle erschwerte. Man kann dabei niemandem Vorwürfe machen - die Überbringer der Nachricht können ja nichts dafür und fanden sich sicher auch nicht gerne in dieser Situation wieder. Vielmehr liegt hier ein Problem der Absprache bzw. der evtl. fehlenden Kapazität vor, solche relevanten Informationen weiterzureichen - und sei es an die Projektmitarbeiter/innen, damit von unserer Seite entsprechend agiert werden kann.

Die fehlende Weitergabe der Information in diesen beiden konkreten Fällen ist sicherlich dem geschuldet, dass unter den Mehrfachbelastungen der CoronaZeit die Kommunikationskanäle überlastet bzw. einfach schlicht die Kapazitäten in den Einrichtungen nicht mehr da waren. Insofern möchte ich hier nicht über mangelndes Einfühlungsvermögen oder fehlende Informationsweitergabe urteilen, dennoch möchte ich auch diese schwere und belastende Auseinandersetzung und daraus resultierende Aufgabe der Aufarbeitung nicht verhehlen. Hier ist m.E. ein besonderes Feingefühl von allen Seiten gefragt. Für die Pflegeheime impliziert dies, dass sie die Perspektive der studentischen Teilnehmer/innen einnehmen und damit ihre professionelle Sicht ein Stück weit verlassen bzw. von dieser abstrahieren müssen. Für sie gehört das Sterben von Bewohner/innen zum zwar traurigen, aber dennoch Bestandteil des Pflegeberufes. Für die Student/innen ist dies nicht der Fall. Im Gegenteil: Sie lassen sich ja gerade auf die emotionale Beziehung mit ihrer besuchten Person ein und empfinden einen Verlust, wenn diese fehlt. Einen solchen Verlust zu begleiten ist auch für mich traurig, aber ein Bestandteil der Projektarbeit. Auch hier suche ich den direkten persönlichen Austausch und stehe mit Gesprächsangeboten und ggf. Vermittlung an andere Stellen zur Verfügung. 
Bislang konnten diese traurigen Momente aufgefangen werden, dabei zeigte sich u. a. auch, dass die studentischen Teilnehmer/innen sehr differenziert und gefasst mit der Thematik umgehen und ihrerseits auf ein gut funktionierendes soziales Netzwerk zurückgreifen konnten, das sie unterstützte.

Das Projekt prägt alle Teilnehmer/innen und führt zu einem Zuwachs an Selbstreflexion, Empathiefähigkeit und auch Resilienz. Einblicke lassen sich aus den regelmäßig im Rahmen der Evaluation schriftlich erhobenen studentischen Reflexionen herauslesen, aus denen ich an dieser Stelle exemplarisch zitieren möchte. Ein übergreifender Punkt ist dabei die Rückmeldung Vieler, dass sie Ängste vor Alterserkrankungen abgebaut und ein Verständnis für die ältere Generation erlangt haben, sie berichten von emotionalen Situationen und tiefen Erfahrungen, die sie vorher nicht für möglich gehalten haben. Das Zitat einer Teilnehmerin fasst dabei die Tiefe und auf besondere Weise auch die Freude hinter den Begegnungen sehr schön zusammen:

„UnVergessen - Das war genau das richtige Projekt für mein Studium ... weil das Lachen eines anderen Menschen mehr zählt als Arbeiten und CPs.“

Die Studierenden erwerben Kompetenzen in einer neuen Weise und auch Tiefe. Dies spricht auch aus den Rückmeldungen, die ich von Teilnehmer/innen der Aktion Briefe gegen die Einsamkeit bekommen habe. Ein Student schrieb mir, wie er über das Schreiben seiner Briefe in einen Prozess der Selbstreflexion gekommen ist:

„Ich mache mir Gedanken darüber, was es eigentlich heißt, mit jemandem in Kontakt zu treten und auf welche Weise wir dies tun. Inwiefern verändert sich das in der aktuellen Zeit und wie kann ich es schaffen, über den Brief jemandem zu zeigen, wer ich bin.“

Eine andere Person resümiert im Gruppenforum:

„Es ist schon interessant, wie unsere Seelen danach streben, mit jemandem in Kontakt zu treten und sich wünschen, von ihm eine Antwort zu bekommen ..."

Diese Zitate geben Einblicke in die durch das Projekt angestoßene Reflexionsarbeit. Damit steht für mich die Erkenntnis, dass durch das Projekt nicht bloß die Gruppe der pflegebedürftigen Teilnehmer/innen durch die ihnen gewidmete Zeit und Aufmerksamkeit profitiert, sondern auch die studentischen Teilnehmer/innen einen Mehrgewinn erfahren. Zusätzlich profitieren die Pflegeheime in unterschiedlicher Weise (mehr dazu ist im folgenden Teil des Bandes zu lesen) und es 
erwachsen für die Wissenschaft neue Möglichkeiten und Forschungsfelder (wie bereits oben ausgeführt wurde). Vor diesem Hintergrund möchte ich zu meiner ursprünglichen Vision, Brücken zwischen Institutionen, Generationen, Menschen und Sprachen zu bauen zurückkehren. Diese Brücken sind geschlagen und die Wissenschaft hat sich hinzugesellt.

\section{Literatur}

Anstatt, T. (2007). Mehrsprachigkeit bei Kindern und Erwachsenen. Erwerb, Formen, Förderung. Attempto Verlag.

Batler, J. (2020). Generationen im Vergleich. Gemeinsamkeiten zwischen verschiedenen Generationen an Hand von Briefen und einer Umfrage aufgeführt [Unveröffentlichte Hausarbeit]. Ruhr-Universität Bochum.

Bialystok, E., \& Sullivan, M. D. (2017). Growing old with two languages: Effects of bilingualism on cognitive aging. John Benjamins. https://doi.org/10.1075/sibil.53.

Feimer, J. (2005). Manumotorische Untersuchungen von Schriftproben bei Patienten mit Demenz vom Alzheimer-Typ und Patienten mit leichten kognitiven Störungen im Vergleich zu gesunden Probanden [Dissertation zum Erwerb des Doktorgrades, LudwigMaximilians-Universität zu München]. Elektronische Hochschulschriften. https://edoc. ub.uni-muenchen.de/4439/1/Feimer_Jan.pdf.

Harin, K. (2020). UnVergessen. Sprache im Alter und im Pflegeheim unter Berücksichtigung von Mehrsprachigkeit [Unveröffentlichter Erfahrungsbericht]. Ruhr-Universität Bochum.

Karl, K. B. (2012). Bilinguale Lexik: Nicht materieller lexikalischer Transfer als Folge der aktuellen russisch-deutschen Zweisprachigkeit. Verlag Otto Sagner.

Karl, K. B. (2020, Juli 09). Universitäres Engagement gegen Einsamkeit und Vergessen. In BBE Newsletter für Engagement und Partizipation in Europa. https://www.b-b-e.de/eur opa-nachrichten/europa-nachrichten-nr-6-vom-972020/karl-universitaeres-engagementgegen-einsamkeit/vergessen/.

Karl, K. B., \& Behrens, Y. (06 Juni 2019). Erstellung und Evaluation eines Sprachenkörpers als Hilfestellung im mehrsprachigen Pflegealltag [Vortrag]. Kolloquium zur Mehrsprachigkeitsforschung an der TU Dortmund.

Karl, K. B., \& Behrens, Y. (09 September 2019). Einsatz eines Sprachenkörpers zur Unterstützung im mehrsprachigen Pflegealltag [Vortrag]. Fachtagung der Deutschen Gesellschaft für Gerontologie und Geriatrie (DGGG) in Berlin.

Karl, K. B., \& Behrens, Y. (2020). Das Projekt UnVergessen: Genese, Partizipanten und Forschendes Lernen. In J. Straub, S. Plontke, P. S. Ruppel, B. Frey, F. Mehrabi, \& J. Ricken (Hrsg.), Forschendes Lernen an Universitäten: Prinzipien, Methoden, Best Practices an der Ruhr-Universität Bochum (S. 353-361). Springer VS.

Plejert, C., Lindholm, C., \& Schrauf, R. W. (2017). Multilingual interaction and dementia. Multilingual Matters. https://doi.org/10.21832/9781783097678. 
Posenau, A. (2014). Analyse der Kommunikation zwischen dementen Bewohnern und dem Pflegepersonal während der Morgenpflege im Altenheim. Verlag für Gesprächsforschung.

Reinnert, M. (2020). Inwiefern ist eine Kommunikation mit älteren Menschen, die im Pflegeheim leben, möglich und vor welche Probleme wird man auch im Hinblick auf eventuell vorhandene Einschränkungen der Personen gestellt? [Unveröffentlichter Abschlussbericht]. Ruhr-Universität Bochum.

Sachweh, S. (2006). „Noch ein Löffelchen?“ Effektive Kommunikation in der Altenpflege (2. Aufl.). Huber.

Schreier, M., \& Bollschweiler, F. (2014). Veränderungen der Handschrift bei der Parkinsonkrankheit anhand von sechs Beispielen. Swiss Med Forum, 14(12), 252-258. https://medicalforum.ch/journalfile/view/article/ezm_smf/de/smf.2014.01849/ 97a104dd8206fb819d91545b64dee5c072c53597/smf_2014_01849.pdf/rsrc/jf.

Tusche, A. (2015). Demenz und Migration: Eine Untersuchung zur Kommunikation zwischen einer russischsprachigen Demenzerkrankten und ihren Pflegekräften. [Unveröffentlichte Bachelorarbeit]. Ruhr-Universität Bochum.

Wagner, C. (23. September 2013). Parkinson-Diagnose per Handschrift-Analyse: Israelische Ergotherapeutin will Früherkennung fördern. Deutschlandfunk. https://www.deutschla ndfunk.de/parkinson-diagnose-per-handschrift-analyse.676.de.html?dram:article_id= 262617.

Walther, D. (2019). Der Kalenderbucheintrag als kommunikative Praktik älterer Schreiber/innen. Zeitschrift für Angewandte Linguistik, 71(1), 299-326. https://doi.org/10.1515/zfal2019-2017.

\section{Internetseiten}

https://news.rub.de/studium/2020-07-02-projekt-briefe-gegen-die-einsamkeit.

www.un-vergessen.de

https://www.un-vergessen.de/aktion-briefe-gegen-die-einsamkeit

https://wikis.fu-berlin.de/display/clare/HOME

https://www.helsinki.fi/en/conferences/corpora-for-language-and-aging-research-4) 
Open Access Dieses Kapitel wird unter der Creative Commons Namensnennung 4.0 International Lizenz (http://creativecommons.org/licenses/by/4.0/deed.de) veröffentlicht, welche die Nutzung, Vervielfältigung, Bearbeitung, Verbreitung und Wiedergabe in jeglichem Medium und Format erlaubt, sofern Sie den/die ursprünglichen Autor(en) und die Quelle ordnungsgemäß nennen, einen Link zur Creative Commons Lizenz beifügen und angeben, ob Änderungen vorgenommen wurden.

Die in diesem Kapitel enthaltenen Bilder und sonstiges Drittmaterial unterliegen ebenfalls der genannten Creative Commons Lizenz, sofern sich aus der Abbildungslegende nichts anderes ergibt. Sofern das betreffende Material nicht unter der genannten Creative Commons Lizenz steht und die betreffende Handlung nicht nach gesetzlichen Vorschriften erlaubt ist, ist für die oben aufgeführten Weiterverwendungen des Materials die Einwilligung des jeweiligen Rechteinhabers einzuholen.

(c) (9) 